Personality Development In Old Age Relates to Physical Health and Cognitive Performance: Evidence from the Berlin Aging Study II

\author{
Swantje Mueller ${ }^{1}$, Jenny Wagner ${ }^{1,2}$, Johanna Drewelies ${ }^{1}$, Sandra Duezel $^{3}$, Peter Eibich $^{4}$, \\ Jule Specht ${ }^{5,6}$, Ilja Demuth ${ }^{7}$, Elisabeth Steinhagen-Thiessen ${ }^{7}$, \\ Gert G. Wagner ${ }^{3,6,8}$, \& Denis Gerstorf ${ }^{1,6}$ \\ ${ }^{1}$ Humboldt University of Berlin \\ ${ }^{2}$ Leibniz Institute for Science and Mathematics Education (IPN) \\ ${ }^{3}$ Max Planck Institute for Human Development \\ ${ }^{4}$ University of Oxford \\ ${ }^{5}$ Freie Universität Berlin \\ ${ }^{6}$ German Institute for Economic Research (DIW Berlin) \\ ${ }^{7}$ Charité-Universitaetsmedizin Berlin \\ ${ }^{8}$ Berlin University of Technology (TUB)
}

November 9, 2017

Address correspondence regarding this manuscript to: Swantje Mueller, Humboldt University Berlin, Institute of Psychology, Unter den Linden 6, 10099 Berlin, Germany; phone: +49(0)30-2093-9424; fax: +49-(0)30-2093-9351; swantje.mueller@hu-berlin.de. 


\begin{abstract}
We examine how late-life personality development relates to overall morbidity as well as specific performance-based indicators of physical and cognitive functioning in 1,232 older adults in the Berlin Aging Study II (aged 65-88 years). Latent growth models indicated that, on average, neuroticism and conscientiousness decline over time, whereas extraversion and openness increase and agreeableness remains stable. Higher morbidity and worse grip strength were associated with higher neuroticism. Lower grip strength was further associated with lower openness, attenuated increases in extraversion, decreases in agreeableness and accelerated decline in conscientiousness. Moreover, those with poor perceptual speed reported higher neuroticism and lower conscientiousness. We also found age- and gender-differential associations between physical health and cognitive performance with levels of and changes in personality.
\end{abstract}

Words: 120

Keywords: Personality Traits, Personality Development, Old Age, Health, Cognition, Perceptual Speed 


\section{Personality Development In Old Age Relates to Physical Health and Cognitive Performance: Evidence from the Berlin Aging Study II}

Over the last decades, numerous studies have linked personality traits to health-related outcomes and longevity (Aldwin, Spiro, Levenson, \& Cupertino, 2001; Chapman, B. W. Roberts, \& Duberstein, 2011; Goodwin \& Friedman, 2006; Hampson et al., 2016; Mroczek \& Spiro, 2007; Weiss \& Costa, 2005; Ziegler, Cengia, Mussel, \& Gerstorf, 2015), suggesting that personality may operate as an adaptive capacity that helps people adjust to age-related challenges (Staudinger \& Fleeson, 1996). At the same time, however, lifespan theoretical notions and empirical evidence contend that personality traits themselves are prone to change in the second half of life, as an increasingly negative ratio of gains to losses across multiple domains of functioning threatens the stability of the personality system (Baltes \& Baltes, 1990; Hooker \& McAdams, 2003; B. W. Roberts, Walton, \& Viechtbauer, 2006; Wortman, Lucas, \& Donnellan, 2012). Thus, although personality traits are typically conceptualized as predictors of the onset and progression of disease, it is conceivable that they might also change in reaction to age-related functioning and losses in the health and cognitive domains. Initial evidence suggest that patterns of personality stability and change in the second half of life are indeed related to self-reported chronic diseases and subjective perceptions of health (Jokela, Hakulinen, Singh-Manoux, \& Kivimäki, 2014; Letzring, Edmonds, \& Hampson, 2014), but it is an open question whether and how such associations generalize to performance-based measures of physical health and cognition (for noteworthy exceptions, see Berg \& Johansson, 2014; Mõttus, Johnson, Starr, \& Deary, 2012). In this study, we corroborate and extend these initial findings by applying latent growth models to three-wave, five-year longitudinal data on personality from 1,232 older adults in the Berlin Aging Study II (BASE-II). In particular, we examine mean-level trajectories of the Big Five personality dimensions in old age, investigate the role of overall morbidity as well as specific performance-based indicators of physical and cognitive functioning, operationally defined as 
grip strength and perceptual speed, and test whether age and gender moderate such personality-functioning associations.

\section{Personality Development in Old Age}

While traditional trait models of personality such as the Five Factor Theory of Personality assume personality traits to remain stable after young adulthood (Costa $\&$ McCrae, 1994), theoretical and empirical advances have since led to new conceptualisations of personality continuity and change that integrate trait theory with more dynamic notions of lifespan development (Baltes, Lindenberger, \& Staudinger, 2006; B. W. Roberts \& Wood, 2006; for a recent overview, see Specht et al., 2014). Today, personality is often viewed as an open system that exhibits lifelong plasticity and adaptability and is sensitive to socialisation and contextual experiences throughout life (B. W. Roberts, Wood, \& Caspi, 2008). In particular, it has been suggested that individuals mature in their personality across adulthood and become less neurotic (i.e., more emotionally stable), more conscientious (i.e., planful and deliberate) as well as more agreeable (i.e., charitable and considerate) with age by virtue of adjusting to various social role expectations, experiences, and developmental tasks they encounter at different life-periods (Caspi, B. W. Roberts, \& Shiner, 2005; Hutteman, Hennecke, Orth, Reitz, \& Specht, 2014; B. W. Roberts et al., 2008; Staudinger \& Kunzmann, 2005). In contrast to these maturity-related traits, theories on adult personality development assume that instead of being tied to the mastery of specific developmental tasks, extraversion and openness might increase through processes of personal growth that are not functional per se, but rather reflect the development of certain virtues such as wisdom and self-actualization (Digman, 1997; Staudinger \& Kunzmann, 2005). While maturation is considered to be a normative phenomenon, personal growth has been proposed to occur in some, but not necessarily in most individuals (Baltes et al., 2006; Staudinger \& Kunzmann, 2005).

In line with these theoretical considerations, research over the last decades has consistently shown that personality development is characterized by both continuity and 
change (Lucas \& Donnellan, 2011; B. W. Roberts et al., 2006; Specht, Egloff, \& Schmukle, 2011; Wortman et al., 2012). Consistent with notions of personality maturation, a comprehensive meta-analysis by Roberts and colleagues (2006) revealed that people indeed tend to decrease in neuroticism and increase in agreeableness and conscientiousness across the lifespan, whereas changes in extraversion and openness are often more complex. While

social dominance (one facet of extraversion) increased with age, social vitality (a second facet of extraversion) and openness to experience both increased in adolescence, but started to decline again after age 50 .

More recent investigations mainly confirmed these developmental trends for the first half of life (with a tendency for earlier declines in extraversion and openness; Lucas \& Donnellan, 2011; Specht et al., 2011; Wortman et al., 2012). For old and very old age, however, a different picture emerges. In contrast to young and mid-adulthood, late-life personality development seems to be characterized by a reversal of the maturation trend and accelerated declines in openness and extraversion (Mõttus, Johnson, \& Deary, 2012; Wortman et al., 2012, see also Kandler, Kornadt, Hagemeyer, \& Neyer, 2015; Mroczek \& Spiro, 2003; Wagner, Ram, Smith, \& Gerstorf, 2015). Interestingly, these patterns are not universal, but display considerable individual differences: While some individuals lose the personality maturity reached in midlife, others still exhibit maturation and growth into very old age (Ardelt, 2000; Wagner et al., 2015; Wortman et al., 2012). An important question is which resources or risk factors are associated with these individual differences in the stability and change of personality in old age.

\section{The Role of Physical Health and Cognitive Performance}

Lifespan developmental theory suggests that an increasingly negative ratio of gains and losses in the physical health and cognitive functioning domains constitute key risk factors for personality change late in life (Baltes \& Baltes, 1990; Staudinger \& Fleeson, 1996). In old age, chronic conditions and functional limitations may threaten an individual's capacity to 
maintain an acquired lifestyle and to meet the environmental demands and social role expectations he or she is confronted with, potentially provoking motivational and behavioral changes and adjustments. If persistent, these changes in thoughts, feelings and behavior might in turn prompt long-term personality change in a bottom-up fashion (B. W. Roberts \& Jackson, 2008; B. W. Roberts \& Wood, 2006; Wrzus \& B. W. Roberts, in press).

Physical health. To illustrate, sudden or severe health issues may lead to feelings of vulnerability and anxiety, potentially manifesting in higher levels of neuroticism. Moreover, compromised physical health may force older adults to be more selective in the activities and social relationships they engage in (Wrzus, Hänel, Wagner, \& Neyer, 2013), thereby leading to decreases in extraversion and agreeableness (see Hill, Turiano, Mroczek, \& B. W. Roberts, 2012). Physical health constraints might also limit older individuals' capacity to seek out novel experiences or engage in cultural events and could therefore contribute to decreases in openness to experiences. Similarly, it might be increasingly difficult for individuals in poor physical health to maintain previous levels of orderliness and discipline, resulting in reduced conscientiousness.

These notions are largely supported by a recent meta-analysis $(N=17,493$, mean age $=$ 56) suggesting that individuals become less extraverted, open, and conscientious, but more neurotic after the (self-reported) onset of a chronic disease (Jokela et al., 2014; see also Sutin, Zonderman, Ferrucci, \& Terracciano, 2013). Importantly, the effect of disease on personality development remained significant after adjusting for age. Higher illness burden (i.e., the onset of an additional chronic disease) further accelerated the average age-related change in personality by 2.5 years in declining extraversion, 5.5 years in decreasing conscientiousness, and 1.6 years in decreasing openness, and attenuated decreases of neuroticism by 1.9 years. Similarly, Wagner et al. (2015) reported that poor physical health emerged as a risk factor for declines in extraversion and openness in late life (no association was found for neuroticism; data on agreeableness and conscientiousness were not available). 
Conversely, other studies focusing on very old age groups report little evidence for health-related personality change. Examining personality trajectories from age 81 to age 87 , Mõttus and colleagues found that decreases in physical functioning (operationally defined as a composite measure of grip strength, $6 \mathrm{~m}$ walk time, and forced expiratory volume) were associated with steeper declines in conscientiousness, but unrelated to the other Big Five traits (Mõttus, Johnson, Starr, et al., 2012). Also focusing on the oldest-old, Berg and Johansson (2014) investigated associations of changes in neuroticism and extraversion with a number of subjective and objective health indicators. Notably, only self-rated hearing impairment was associated with accelerated declines in extraversion. However, both studies relied on rather moderate sample sizes $(\mathrm{N}<410)$ and might thus have been underpowered to detect potentially small effects of physical health on personality development. None of the studies reported above found significant associations between physical health and levels or rates of change in agreeableness. Nonetheless, levels of agreeableness have been significantly associated with subjective health in other studies, but with mixed results (Human et al., 2013; Turiano et al., 2012).

In this study, we chose to use more narrow, well defined indicators, which have the advantage that results obtained refer to a clearly circumscribed aspect of functioning rather than to an overall composite of often heterogeneous functional indicators that are difficult to disentangle. Following the logic, we have focused on upper body function as operationally defined by handgrip strength as our indicator of physical functioning. Handgrip strength is a reliable and widely used index of muscle strength and physical functioning that has been linked to various aspects of successful aging, including everyday functioning and mortality (Ambrasat, Schupp, \& Wagner, 2011; H. C. Roberts et al., 2011; Taekema, Gussekloo, Maier, Westendorp, \& de Craen, 2010), and might therefore also be highly relevant in the context of late-life personality development. Please note that although we also had other measures of physical functioning available in this study, these other measures were either reliant on self- 
reports (e.g., Barthel Index) or covered only very narrow and specific aspects of physical functioning (e.g., Tinetti balance test). Because we were interested in examining an objective (here, performance-based) and widely important aspect of physical functioning that potentially impacts older individuals across a variety of different everyday life situations, we thus chose to focus on grip strength as one central indicator of physical functioning.

Cognitive performance. In addition to physical health constraints, age-related declines in cognitive functioning might also contribute to late-life personality change. For example, compromised cognitive resources might limit an individual's capacity to engage in intellectually demanding endeavours or to seek out new and challenging experiences, activities and contexts, leading to decreases in extraversion and openness. Reduced cognitive functioning might further challenge people's ability to make and execute plans, thereby contributing to declines in conscientiousness and increased feelings of anxiety, and thus, higher neuroticism.

These notions are (partially) supported by previous studies, showing that worse cognitive performance is associated with lower and decreasing levels of openness to experience as well as higher levels of or increases in neuroticism (Graham \& Lachman, 2012; Ziegler et al., 2015). Mõttus, Johnson, Starr, and colleagues (2012) further reported that lower IQ was also associated with accelerated decline in conscientiousness. Results for extraversion are mixed. While lower cognitive functioning was associated with higher levels of extraversion in the sample of octogenarians analyzed by Mõttus et al. (2012), Berg and Johansson (2014) found extraversion to be related to better self-reported cognition in a sample aged 80 to 98 , but did not find an association between levels or change in extraversion and performance-based assessments of cognitive functioning. Taken together, theoretical notions and initial empirical evidence suggest that both physical health and cognitive performance may contribute to late-life patterns of personality development. 
In the current study, several reasons have led us to operationally define cognitive performance with perceptual speed. To begin with, measures of perceptual speed have superior psychometric properties (e.g., reliability) compared to other cognitive constructs (see Lindenberger, Mayr, \& Kliegl, 1993), while loading highly on a factor of general intelligence (Salthouse, 1996; Tucker-Drob, Briley, Starr, \& Deary, 2014). Second, perceptual speed is conceptually closer to a resource and more sensitive to cognitive decline in old age than many other cognitive abilities (Hoyer, Stawski, Wasylyshyn, \& Verhaeghen, 2004; Lindenberger \& Ghisletta, 2009). As such, perceptual seed has been shown to predict outcomes across multiple domains of individual functioning, including everyday activities (Aartsen, Smits, van Tilburg, Knipscheer, \& Deeg, 2002; Köhncke et al., 2016), cardiovascular lability (Ram, Gerstorf, Lindenberger, \& Smith, 2011), and mortality (Bosworth, Schaie, \& Willis, 1999). Third, the only other cognitive indicators that were assessed at the beginning of the Berlin Aging Study II (versus later) and could thus have functioned as a potential predictor of subsequent personality change were rather high threshold, pathology-related tests such as the Clock Completion Test or the Mini-Mental State Examination. Because our sample was still relatively well-functioning and because we were interested in how premorbid differences in cognitive functioning may contribute to late-life personality development, we selected the more sensitive measure of perceptual speed as our indicator of cognitive performance.

\section{Age and Gender as Moderators}

Over and above mean-level changes in personality and health across adulthood, it is also conceivable that the strength of personality-health associations varies as a function of age. Specifically, lifespan developmental theory suggests that young old individuals (up until their early 80s; Baltes \& Smith, 2003) still exhibit plasticity and adaptability, allowing them to (partially) buffer and counteract the negative effects of declining health on personality change. However, the impact of health constraints on personality likely becomes more pronounced in old old age (beyond age 80; Baltes \& Smith, 2003), when health issues become 
too pervasive to be compensated by self-regulatory strategies, thus threatening the stability of the personality system (Baltes et al., 2006; B. W. Roberts \& Wood, 2006). To date, empirical studies have rarely tested these conceptual considerations about age operating as a moderator of associations between health and personality development. As one of a few noteworthy exceptions, initial evidence from Wagner et al. (2015) indicates that the predictive effects of health for personality do indeed increase with advancing age. More specifically, the authors report that poor physical health was associated with steeper declines in extraversion in old old, but not in young old individuals.

In addition to age, social role theory (Eagly, 1987) suggests that gender might also moderate associations between health and personality. According to social role theory, an individual's thoughts, feelings, and behavior are influenced by gender-specific roles and expectations about what constitutes appropriate conduct for men and women. For example, the theory suggests that women tend to develop higher levels on traits that encompass friendliness, expressiveness, dependability, and altruism due to stronger social pressure to be communal and sociable. In line with that view, women do indeed report higher average levels of agreeableness, warmth, and conscientiousness (Chapman, Duberstein, Sörensen, \& Lyness, 2007; Schmitt, Realo, Voracek, \& Allik, 2008). In old and very old age, gender differences in social roles might also impact how individuals adapt to losses in the physical and cognitive domains. Because older adults are confronted with an increasingly negative ratio of gains to losses, they need to be more selective in how they invest their limited resources (Baltes \& Baltes, 1990). Following social role theory, women might value and prioritize different domains of functioning than do men, and, for example, invest more energy into maintaining high levels of sociability and diligence (i.e., agreeableness and conscientiousness) when faced with health constraints, thereby reducing the strength of personality-functioning associations for these traits. To our knowledge, no study to date has systematically examined whether 
gender moderates how performance-based indicators of physical health and cognitive functioning relate to personality change in old age.

\section{The Present Study}

In the present study, we investigate three sets of questions by applying latent growth models to three-wave, five-year longitudinal data on personality from 1,232 older adults in the BASE-II. In a first step, we examine stability and change in the Big Five personality dimensions. In line with previous research, we expect to find mean-level declines in all Big Five traits but neuroticism. Because neuroticism has been found to decrease until approximately age 80 and then increase again (e.g., Mroczek \& Spiro, 2003) and given the age range of our sample (65 to 88 years), we expect mean levels of neuroticism to either remain stable or decrease only marginally.

In a second step, we examine the role of specific physical health and cognitive functioning indicators. Acknowledging that subjective evaluations and more performancebased objective health assessments often differ considerably in old age (Baltes \& Smith, 2003; Steinhagen-Thiessen \& Borchelt, 1999), our study is in the rare position to examine the role of overall morbidity as well as specific performance-based indicators of physical and cognitive functioning, here operationally defined as grip strength and perceptual speed, respectively. We expect poor grip strength and perceptual speed to be associated with higher levels of and stronger increases in neuroticism as well as with lower levels of and accelerated decline in extraversion, openness, and conscientiousness. We also explore the role of these variables for levels and change in agreeableness, but do not make any specific predictions because prior evidence using subjective health ratings was mixed. In a final step, we test whether age and gender moderate such personality-functioning associations.

\section{Methods}

\section{Participants}


Data were drawn from the BASE-II. A detailed description of the overall study design, sampling methods, variables, and procedures can be found in Bertram et al. (2014) and Gerstorf et al. (2016). Participants were recruited from the greater metropolitan area of Berlin via advertisements in regional newspapers and public transportation systems as well as through a participant pool at the Max Planck Institute for Human Development. Personality assessments were obtained as part of a larger psychosocial assessment battery. Most participants completed the questionnaire at home either through an online tool or as a paperpencil version (according to their preferences). A small number of participants (less than 5\%) answered the items in face-to-face interviews. Medical information was obtained in a hospital through a two-day protocol including a wide range of laboratory and functional tests as well as a comprehensive anamnesis performed by a physician.

Three waves of personality data (assessed in 2009, 2012, and 2013-2014) and one wave of health data (mostly collected between wave 1 and 2) were available for this study. We note that approximately $80 \%$ of participants completed their health assessment between wave 1 (2009) and wave 2 (2012). 20\% of participants completed the test protocol after the second wave. To ensure that our results are not biased by the timing of the health assessment, we included the date of the health assessment as a covariate in all analyses. In follow-up analyses, we additionally estimated our models with only the subsample of participants who had completed the health assessment early in the study (between wave one and two) and used only the two waves of personality data that were collected after the health assessment. This did not affect the overall pattern of results, but several coefficients were not statistically significant anymore due to the reduced sample size and statistical power (for details, see Table S2 in the online supplementary material).

Included in our analysis sample were all BASE-II participants aged 65 or older who provided at least one personality assessment, resulting in a final sample of 1,232 participants aged 65 to $88(M=71, S D=3.48,52 \%$ women, $56 \%$ married $)$. Among participants aged 70 
years or younger, $41 \%$ of the women and $70 \%$ of the men reported to be married. Among older participants, the percentage increased slightly for men $(75 \%)$, but decreased for women (37\%). Because of our interest in late-life personality, the younger subgroup of BASE-II (aged 20-35) was not considered here. Compared to same-aged participants from the nationally representative German Socio-Economic Panel (SOEP), participants in our study were significantly better educated (Cohen's $d=0.91)$, less neurotic $(d=0.22)$, more extraverted $(d=0.17)$ and open to experience $(d=0.41)$ as well as less agreeable $(d=0.23)$ and conscientious $(d=0.38)$.

While the majority of BASE-II participants was recruited in 2009, some participants joined the study later in an ongoing recruitment process. As a consequence, the BASE-II sample grows larger across waves $\left(\mathrm{N}_{2009}=769, \mathrm{~N}_{2012}=950, \mathrm{~N}_{2013 / 4}=1,232\right)$. We have taken several steps to characterize and accommodate the structure of our data. To begin with, we have centered the intercepts of our models at the last assessment wave. We have also thoroughly quantified the selectivity of our sample. In particular, participants who joined later completed the same medical and cognitive test protocols, but provided fewer waves of personality data than the initial sample recruited in 2009. Compared to participants who started in 2009, participants who were recruited after 2009 were more likely to be men $(d=$ $.54)$, were a little younger $(d=.37)$, slightly less neurotic $(d=.17)$, more open to experience $(d=-.15)$ and showed worse performance on the perceptual speed test $(d=.33)$ but better grip strength $(d=-.48)$. There was almost no longitudinal attrition: $97.92 \%$ of the individuals who participated in wave 1 (2009) also participated in wave 3 (2013/4). Overall, 956 (78\%) out of the 1,232 BASE-II participants provided at least two waves of personality data, and $660(54 \%)$ participants contributed three waves of data.

We based our analyses on all available information, including participants who only provided one personality assessment, and used full-information maximum likelihood (FIML) estimation to deal with missing values. We did so for two reasons. First, including all 
available cases maximizes statistical power and thus facilitates the detection of potentially small effects. Second, FIML has been demonstrated to be a powerful algorithm for handling missing values (Enders \& Bandalos, 2001; Schafer \& Graham, 2002). Even if data are not missing at random, FIML tends to produce less biased parameter estimates than traditional procedures such as listwise deletion. Rather than deleting cases or imputing missing values, the FIML estimator recognizes missing observations as such and uses all available information, even for participants with missing values on some of the variables of interest (Enders, 2010).

\section{Measures}

Personality. Personality was assessed using a German short version of the Big Five Inventory (BFI-S; Gerlitz \& Schupp, 2005; John \& Srivastava, 1999; see also Lang, John, Lüdtke, Schupp, \& Wagner, 2011). The BFI-S contains three items for each of the five factors that were answered on a 7-point Likert scale ranging from 1 (strongly disagree) to 7 (strongly agree). The BFI-S was designed for use in large surveys and displays acceptable reliability and validity in comparison with the German adaption of the NEO-FFI and other criteria (Gerlitz \& Schupp, 2005). Importantly, the BFI-S has also been shown to be robust across different methods of data collection (Hilgert, Kroh, \& Richter, under review; Lang et al., 2011). That is, the factor structure of the Big Five model generalizes across selfadministrative procedures and face-to-face interviewing, indicating that personality ratings should not be affected by the assessment method used. Cronbach's alphas for the five subscales were modest (Neuroticism, $\alpha=.70$; extraversion $\alpha=.69$; openness, $\alpha=.67$; agreeableness, $\alpha=.54$; conscientiousness, $\alpha=.63$; values were averaged across the three measurement occasions), reflecting the heterogeneity of the items selected to measure relatively broad constructs. In order to account for the moderate reliability of the scales, we followed Lang et al. (2011) and modeled personality factors as latent variables. 
Socio-demographic characteristics. Age was computed as the difference between the date of a participant's last personality assessment and his or her date of birth, scaled in years. Gender was coded 0 for men and 1 for women. Education was measured as number of years spent in formal schooling.

Morbidity. As part of the medical examination at the Charite university hospital Berlin, diagnoses were obtained through participant reports, with select diagnosis (e.g., diabetes mellitus) being verified by additional (blood-laboratory) tests (for details, see Bertram et al., 2014). Diagnoses were used to compute a morbidity index largely based on the categories of the Charlson index, which is a weighted sum of moderate to severe, mostly chronic physical illnesses, including cardiovascular (e.g., congestive heart failure), cancer (e.g., lymphoma), and metabolic diseases (e.g., diabetes mellitus). Each disease is assigned a number based on the severity of the condition (e.g., 1 for myocardial infarct, diabetes, ulcer or chronic liver disease, 2 for diabetes with end organ damage, tumor or lymphoma, 3 to moderate or severe liver disease etc.; for details, see Charlson, Pompei, Ales, \& MacKenzie, 1987 and Meyer et al., 2016).

Grip Strength. Grip strength was assessed as the average force applied to a hand dynamometer (Smedley) over three trials with the dominant hand. The force exerted was measured in kilograms ( 0 to $100 \mathrm{~kg})$.

Perceptual speed. We used test scores on the Digit Symbol subtest of the Wechsler Adult Intelligence Test (WAIS; Wechsler, 1955) to assess perceptual speed. The test involves substituting symbols for numbers following a coding scheme. Participants were given 90 seconds to fill as many boxes as possible with the appropriate symbols. The score was then calculated by subtracting the number of errors from the number of correctly filled boxes (for details, see Gerstorf et al., 2015).

Descriptive statistics and intercorrelations of all variables under study are presented in Table 1 (for intercorrelations between personality, health and demographic variables) and 
Table 2 (for intercorrelations of personality traits across time). Two aspects are of note. First, looking at the zero-order correlations displayed in Table 1, only few personality-functioning associations reached significance. Specifically, higher neuroticism at the last assessment wave was associated with higher morbidity and lower grip strength. In addition, people with better grip strength reported lower levels of agreeableness and participants with better perceptual speed were higher on conscientiousness. Second, intercorrelations among the three health and functioning indicators were small or non-significant $(r \leq|.10|)$, suggesting that these variables indeed tap into different facets of the overarching physical health and cognitive functioning construct space.

\section{Analytic strategy}

All hypotheses were tested based on second-order latent growth models estimated in Mplus 7.1 (Muthén \& Muthén, 1998-2012). Identical models were constructed for each personality trait. As a precondition for all further hypotheses testing, strict factorial invariance was tested (Meredith \& Teresi, 2006; Widaman, Ferrer, \& Conger, 2010) and confirmed for all traits all $(\mathrm{CFI}>.98, \mathrm{TLI}>.98, \mathrm{RMSEA}<.04, \mathrm{SRMR}<.06$; see Table $\mathrm{S} 1$ in the online supplementary material).

After establishing measurement invariance, our research hypotheses were tested in three steps: As a first step, changes in personality were examined using second-order latent growth models as illustrated in Figure 1 (see Ferrer, Balluerka, \& Widaman, 2008). Specifically, we extended the measurement models by adding a latent intercept factor reflecting the personality trait level at the last assessment wave and a latent slope factor reflecting mean-level changes over time. The intercept was estimated based on the last as opposed to the first wave to better suit our data structure and research question (see Newsom, 2015). Please note that intercepts are usually centered at the point in time when data have most frequently been collected, so as to increase statistical power and reliability of the model. Because typically sample sizes are 
largest at the first wave of assessment, empirical reports oftentimes center their models at the first wave. In contrast, the structure of our data is different, with the sample size being largest at the last wave of assessment (due to the ongoing recruitment process and almost complete absence of longitudinal dropout). In addition to these methodological considerations, choosing the last wave as a reference for the intercept aligns well with our research question which focuses on how different health domains might relate to subsequent personality trait levels (and changes). Nonetheless, we also estimated an additional set of follow-up analyses in which the intercept was centered at $\mathrm{T} 1$. The different centering did not affect the pattern of change trajectories reported in the manuscript.

Because time intervals between assessment waves varied across individuals, we used the TSCORE option of the Mplus software (Muthén \& Muthén, 1998-2012) to implement individually varying instead of fixed slope factor loadings. With this option, the time structure of the latent growth model is not based on measurement occasion, but relies on observed individual specific timing scores (i.e., TSCORES) contained in the data set which specify when the individual measurements took place. Compared to classical latent growth models, this time modeling approach is more similar to the setup used in multilevel modeling software, allowing for the accommodation of individual differences in assessment intervals. As a consequence, these models estimate only unstandardized effects and do not provide information on absolute fit indices such as CFI, TLI, or RMSEA. We thus only report Aikaike's Information Criterion (AIC) as a relative fit index. To facilitate parameter interpretation, we manually transformed unstandardized covariances into correlation coefficients (by dividing the covariance of two variables by the product of the square root of the variance of the first variable and the square root of the variance of the second variable) and report these in the results section alongside the unstandardized parameters.

As a second step, the three health variables were included as correlates of the intercept and slope factors to test associations of personality trait levels and changes with morbidity, 
grip strength, and perceptual speed. As a final step, we simultaneously added age, gender, and education (all mean-centered) as predictors of intercept and slope to control for demographic background. In addition, we also tested for all possible health $\times$ age and health $\times$ gender interactions. Correlations between health and demographic variables were included if significant.

Because the area of personality trait development in old and very old age is still underexplored, we think that it might benefit the field to allow even small effects to surface. We therefore chose a relatively liberal significance level and report all effects that are significant at $p<.05$. Given that research on associations between personality development and health is still in its infancy and considering the scarceness of performance-based indicators of health available in this study, potential type 2 errors (not finding a true effect) might be particularly harmful as they could discourage future investigations in this direction (see Mõttus, Johnson, Starr, et al., 2012). In contrast, if our rather liberal approach leads to type 1 errors, future studies will be able to test to what extent the effects replicate.

\section{Results}

We report our results in three steps. First, we describe patterns of mean-level stability and change as found in our sample and summarize how these patterns differ by demographic variables. Second, we report associations between personality traits and their changes with morbidity, grip strength, and perceptual speed. Finally, we describe how these associations were moderated by age and gender.

\section{Personality Development in Old Age}

Results from latent growth models used to test our first research question are presented in Table 3. As can be seen, four out of five personality traits showed small mean-level changes over the observed period of five years. Specifically, neuroticism and conscientiousness decreased over time, whereas extraversion and openness increased. The largest average change was observed for neuroticism, which decreased an average of -0.05 
scale points per year on the $1-7$ scale used (i.e., -0.5 scale points per decade). Using the standard deviation for a given variable at the first assessment wave as a reference (see Table 1 and 2), the total amount of personality change across the five years was $-0.19 S D$ for neuroticism, $0.09 S D$ for extraversion, $0.08 S D$ for openness and $-0.10 S D$ for conscientiousness. No significant mean-level changes were found for agreeableness.

Each trait displayed significant interindividual differences in intercepts and rates of change. To better understand the magnitude of variation, we calculated the $95 \%$ plausible value range of the slopes, following Raudenbush and Bryk (2002, p. 78). For 95\% of our sample, the slope parameters for neuroticism ranged between -.33 and .23 , indicating that although we find mean-level decreases in neuroticism, a substantial number of participants actually increased in this trait over time. Similarly, extraversion (-.18 to .22$)$, openness (-.18 to .22 ), agreeableness (-.19 to .21), and conscientiousness ( -.22 to .18) demonstrated considerable variation, illustrating the heterogeneity of personality trajectories in old age.

Associations of demographic variables with mean level (intercept) and mean-level change (slope) are shown in Table 4. On average, older participants reported lower levels of extraversion as well as lower levels of and reduced increases in openness. Further, women showed higher levels of neuroticism, extraversion, and agreeableness as well as accelerated decline in conscientiousness. Participants with higher educational attainment were less extraverted and agreeable, but did not differ in rates of change in any of the five traits.

\section{The Role of Morbidity, Grip Strength, and Perceptual Speed}

Associations of morbidity, grip strength, and perceptual speed with mean level (intercept) and mean-level change (slope) of personality traits are also shown in Table 4. Results revealed that higher morbidity $(\gamma=0.09,95 \%$ CI $[0.05 / 0.13], r=.15)$ and lower grip strength $(\gamma=-0.59,95 \%$ CI $[-0.97 /-0.21], r=-.06)$ were each uniquely associated with higher neuroticism at the last assessment wave. Worse grip strength was further correlated with lower levels of openness $(r=0.35,95 \%$ CI [0.01/0.69], $r=.04)$, attenuated increases in 
extraversion $(\gamma=0.11,95 \%$ CI [0.04/0.17], $r=.13)$, decreases in agreeableness $(\gamma=0.08$, $95 \% \mathrm{CI}[0.02 / 0.14], r=.10)$, and accelerated decline in conscientiousness $(\gamma=0.07,95 \% \mathrm{CI}$ $[0.00 / 0.14], r=.09)$. Additionally, individuals with lower perceptual speed reported higher levels of neuroticism $(\gamma=-0.89,95 \%$ CI $[-1.50 /-0.28], r=-.10)$ as well as lower levels of conscientiousness $(r=0.66,95 \% \mathrm{CI}[0.20 / 1.11], r=.10)$. In sum, morbidity, grip strength, and perceptual speed were each associated with late-life personality trait levels, but only grip strength was related to rates of change in personality.

\section{Age and Gender as Moderators}

An even more differentiated picture of personality-functioning associations emerged when looking at age- and gender-moderated effects (see Figures 2 and 3). Age moderated the association between grip strength and agreeableness $(r=-1.87,95 \% \mathrm{CI}[-3.45 /-0.27], r=-$ .08), such that compromised grip strength was associated with higher levels of agreeableness in older, but not younger participants (see Figure 2 Panel a). In contrast, higher morbidity was associated with accelerated decline in conscientiousness in young old, but not in old old individuals $(\gamma=0.02,95 \%$ CI $[0.00 / 0.05], r=.13$; see Figure 2 Panel b). Age further moderated associations between perceptual speed and changes in extraversion $(\gamma=0.37,95 \%$ CI $[0.03 / 0.71], r=.14)$ and conscientiousness $(r=0.38,95 \%$ CI $[0.05 / 0.71], r=.15$; see

Figure 2 Panel $\mathrm{c}$ and d), such that lower perceptual speed was associated with stronger increases (or attenuated decline) in extraversion and conscientiousness in young old participants, while old old individuals with compromised perceptual speed reported stronger decreases (or reduced increases) in both traits.

We further found gender-differential effects for grip strength and agreeableness $(\gamma=$ $0.19,95 \%$ CI [0.06/0.32], $r=.10)$ : Worse grip strength was associated with lower agreeableness in women, but with higher agreeableness in men (see Figure 3 Panel a). Additionally, women with higher morbidity showed attenuated increases in agreeableness, whereas the reverse was true for men $(r=-0.004,95 \%$ CI $[-0.01 /-0.00], r=-.17$; see Figure 
3 Panel b). Finally, gender also moderated the association between grip strength and rates of change in conscientiousness $(\gamma=-0.04,95 \% \mathrm{CI}[-0.07 /-0.00], r=-.15)$, such that the decline in conscientiousness among those with poor grip strength was primarily found among men (see Figure 3 Panel c). Taken together, our results indicate personality-functioning associations for agreeableness and conscientiousness manifest differently across age groups and gender.

\section{Discussion}

The major objective of our study was to examine associations of overall morbidity as well as specific performance-based indicators of physical health and cognitive functioning with later-life personality traits and their changes. To do so, we applied latent growth models to three-wave, five-year longitudinal data from 1,232 older adults in the BASE-II (aged 65-88 years, $M=71,52 \%$ women). Our findings revealed that, on average, neuroticism and conscientiousness decline over time, whereas extraversion and openness to experiences increase and agreeableness remains stable. In addition to mean-level changes, there were significant individual differences in levels and rates of change in each trait. Intriguingly, our results indicate that these patterns of personality stability and change are associated with morbidity, grip strength, and perceptual speed. In line with our expectations, higher morbidity and lower grip strength were each uniquely associated with higher neuroticism. Worse grip strength was further associated with lower levels of openness, attenuated increases in extraversion, decreases in agreeableness, and accelerated decline in conscientiousness, whereas individuals with lower perceptual speed reported higher levels of neuroticism and lower levels of conscientiousness. In addition, we also found evidence for age- and genderdifferential effects. We discuss conceptual and practical implications arising from our findings that substantial across-domain associations of physical health and cognitive functioning variables exist with later-life personality development. 
Our results on mean-level stability and change in personality in old age are in line with previous research, suggesting that personality trajectories in old age are multidirectional (Lucas \& Donnellan, 2011; Specht et al., 2011; Wortman et al., 2012). Compared to previous longitudinal investigations, mean-level trends observed in this sample are slightly different though. Other studies have reported a reversal of the maturity principle as well as accelerated declines in extraversion and openness in old and very old age (Kandler et al., 2015; Mõttus, Johnson, \& Deary, 2012; Mroczek \& Spiro, 2003; Wagner et al., 2015; Wortman et al., 2012). In contrast, our results indicate normative decreases in neuroticism, stability in agreeableness, increases in extraversion and openness, and indeed select evidence for declining personality maturity on conscientiousness. One possible reason for such discrepancy may be that our sample is slightly younger and probably more positively selected (particularly on neuroticism, extraversion, and openness; for details, see sample description).

To illustrate, Mõttus, Johnson, and Deary (2012) found significant mean-level declines in extraversion, agreeableness, and conscientiousness in an older cohort aged 81 to 87 years of age, while the younger cohort aged 69 to 72 reported increases in extraversion and no significant changes in the other Big Five traits. Similarly, Wortman et al. (2012) found pronounced declines in agreeableness and extraversion mainly after age 70 and 80 , respectively, while increases in neuroticism where only observed in individuals older than 80 . Although our sample covers an age range from 65 to 88 , half of our participants were 70 years old or younger and $90 \%$ were under 80 years of age, which might have led to slightly different mean-level trajectories compared to those reported in studies that had included a higher propotion of very old participants. Supporting this view, patterns of personality development observed in our study were moderated by age, with older adults reporting lower levels of extraversion and openness as well as attenuated increases in the latter trait. Consistent with theoretical notions (Eagly, 1987) and prior empirical evidence (Chapman et al., 2007; Schmitt et al., 2008), levels and change in personality also differed across gender, 
such that women showed higher levels of neuroticism, extraversion, and agreeableness as well as attenuated decline in conscientiousness.

\section{The Role of Morbidity, Grip Strength, and Perceptual Speed}

Morbidity and grip strength. Intriguingly, our results also provide empirical evidence for long-standing notions that indicators of physical health and cognitive functioning play a considerable role for stability and change in later life personality (Baltes et al., 2006). Specifically, our findings suggest that morbidity and grip strength may serve as a buffer (or risk factor, if lacking) for personality development in old age, being significantly associated with all of the Big Five traits. Grip strength was also the only health variable related to rates of change in personality and not only the trait levels. Interestingly, when looking at the main effects, morbidity was only associated with lower levels of neuroticism but did not show significant associations with any of the other traits, indicating that late-life personality development might be more strongly related to aspects of functional health, rather than to the presence or absence of disease per se.

Speaking to the importance of considering different health aspects separately, Wagner et al. (2015) found that participant reports of functional limitations were more closely associated with personality change than physician-assessed medical diagnoses. It is also possible that the number and severity of chronic conditions is more strongly related to personality in particularly vulnerable individuals who have fewer resources to buffer the deleterious effects of poor health (cf. Jokela et al. 2015). In line with this notion, Wagner et al. (2015) found that morbidity predicted stronger decreases in extraversion in individuals in their mid-eighties and older, but not in young old individuals (see also below for our discussion of age-differential effects).

Perceptual speed. In addition to morbidity and grip strength, perceptual speed was also associated with levels of, but not rates of change in late-life personality. Mirroring findings from previous research (Graham \& Lachman, 2012; Mõttus, Johnson, Starr, et al., 2012), 
individuals with lower perceptual speed reported higher levels of neuroticism and lower levels of conscientiousness, suggesting that declining cognitive resources in old age may provoke feelings of anxiety (higher neuroticism) as well as challenge an individual's ability to maintain high levels of planning and diligence (reduced conscientiousness). However, we found no association between perceptual speed and openness to experience, which stands in contrast to previous reports suggesting that fluid abilities are an important resource for openness late in life (Wagner et al., 2015; Ziegler et al., 2015).

One potential explanation for this discrepancy could lie in the characteristics of our sample, which is still relatively young compared to the participants from previous studies. Compared to a nationally representative sample of the German population, our participants are also positively selected on education $(d=0.91)$ and openness to experience $(d=0.41)$, which in turn could result in reduced associations between our measure of fluid intelligence and openness. Moreover, the diverging findings might also reflect differences in measures. Specifically, while the intellect aspect of openness has the greatest conceptual and empirical overlap with cognitive abilities (DeYoung, 2011), our measure of openness focuses more on open-mindedness, creativity, and vivid imagination, which might be less sensitive to agerelated cognitive decline than the intellect facet. Additionally, the measurement interval used in this study might not have been optimal to capture associations between perceptual speed and changes in openness. It may take several years for age-related cognitive declines to shape people's openness in detectable ways, and thus associations might be more easily captured within a longer-term study period (e.g., 13 years, Wagner et al., 2015; but see Jackson, Hill, Payne, Roberts, \& Stine-Morrow, 2012 who reported that cognitive training was associated with personality change across 30 weeks).

\section{Age and Gender as Moderators}

The role of age. Our results are consistent with conceptual notions and empirical evidence suggesting that personality-health associations manifest differently among very old 
people as opposed to those in their late 60s and early 70s. To illustrate, our age-differential findings for agreeableness are in line with theoretical notions suggesting that personality and health are more closely intertwined as people grow older because they have less resources available to buffer or compensate the deleterious effects of poor health (Baltes \& Smith, 2003). In contrast, however, our result that declines in conscientiousness were stronger among the young old as opposed to the old old were unexpected. A possible explanation could be that conscientiousness is particularly vulnerable to health-related changes in a specific period of life that is also characterized by potentially destabilizing social transitions. For example, the transition into retirement which normatively occurs when people are in their mid-60s (in Germany) has previously been associated with more pronounced decreases in conscientiousness (Specht et al., 2011). It is thus possible that young old individuals who simultaneously face both changes in social roles and everyday routines as well as increasing difficulties in the health domain are more prone to declines in conscientiousness than are older adults living in more stable contexts.

Interestingly, age-moderated associations between perceptual speed and changes in extraversion and conscientiousness suggest that young old and old old participants might also adapt differently to compromised cognitive resources. It is upon future, more mechanismoriented research to delineate more specifically whether and how young old participants with higher reserve capacity (e.g., Baltes \& Baltes, 1990) might be able to compensate reduced cognitive resources in the fluid intelligence domain by focusing more on social activities and by increasing their efforts in planning and structuring their everyday lives, which in turn may result in increases in extraversion and attenuated declines in conscientiousness. Old old individuals, in contrast, show the reversed pattern of results, reporting lower increases in extraversion and stronger declines in conscientiousness, which might be due to the age-related depletion of reserve capacity and compensatory resources. 
The role of gender. In addition to age-differential effects, we also observed gendermoderated associations for agreeableness and conscientiousness. Interestingly, our results largely converge with previous findings from Jerram and Coleman (1999), who reported that agreeableness was associated with better subjective health in women, but not in men, whereas conscientiousness was associated with better health perceptions in men only. Similarly, we found that women with compromised physical health reported lower levels of and stronger decreases in agreeableness, whereas the reverse was true for men. This might suggest that rather than social roles (cf. Eagly, 1987) driving gender-differential associations between agreeableness and health in old age, men and women might rely on different coping strategies and resources. Because women tend to have larger social networks and receive support from multiple sources (Antonucci \& Akiyama, 1987), and given that they often exhibit higher levels of agreeableness than men to begin with, they might be able to "afford" becoming relatively less agreeable, altruistic, and compliant without losing the social support they need in order to cope with their compromised physical health. In contrast, men tend to have smaller social networks and lower average-levels of agreeableness, which may prompt them to increase in agreeableness as their health declines in order to secure the social support they increasingly depend on.

In addition to gender-differential associations for agreeableness, we also found that the association between compromised grip strength and accelerated decline in conscientiousness is primarily driven by men. This finding is in line with social role theory (Eagly, 1987) and potentially indicates that women are more socially motivated than men to maintain high levels of orderliness and diligence even in the face of reduced physical resources, leading to smaller associations between health and changes in conscientiousness in women as compared to men. However, it should be noted that most of the interaction effects observed in our sample are very small, were significant at the $p<.05$ level only despite our relatively large sample, and should therefore be interpreted with caution. More research is needed to corroborate these 
findings and investigate which mechanisms might drive such age- and gender-differential effects.

Overall, the current findings indicate that specific indicators of physical health and cognitive functioning might serve as important resources (or risk factors, if lacking) for latelife personality, with grip strength as an indicator of physical functioning being particularly relevant for personality change in old age. Specifically, individuals with better performance in physical health and cognitive functioning domains appear to maintain higher levels of personality maturity and even show some increases in maturity and personal growth up until old age, whereas individuals suffering from more severe health constraints seem more prone to decline in maturity-related traits. This supports notions from lifespan developmental theory (e.g., Baltes et al., 2006) suggesting that gain-loss dynamics play an important role in shaping late-life personality development and contribute to the transition from personality maturation and growth to patterns of adaptation (for a more detailed discussion of adaptive personality change late in life, see Mueller, Wagner, \& Gerstorf, in press).

\section{Limitations and Outlook}

The current study was in the rare position to analyze associations between personality development and health in a large community-dwelling sample of older adults who provided performance-based indicators of physical and cognitive functioning. However, we also note several key limitations of our study. To begin with limitations in the design, our health data were not exclusively assessed at wave 1 , which complicates the interpretation of the directionality of results. Nonetheless, given that limitations in physical health and cognitive functioning often develop over longer periods of time and are preceded by prolonged periods in which risk factors and subclinical form of impairment are already present, we argue that if health data had been obtained a year or two earlier, a similar pattern of results would have emerged. Moreover, we addressed this issue empirically by including the time of health assessment as a covariate in all analyses and also confirmed the pattern of results in follow-up 
analyses containing only those participants who had their health assessment early in the study and using only the personality information that was collected after the health data. As can be obtained from the online supplementary material, these two-wave latent change models broadly confirmed our pattern of results: All 15 personality-health associations were similar in size and direction to those reported in the full three-wave models. However, due to the different model set up and the reduced sample size and statistical power, 8 out of 15 personality-health associations were not statistically significant anymore.

Still, because we had only one wave of health data available for this study we are unable to draw any inferences about the temporal ordering of personality-health associations. For example, it is well possible that health variables not only operate as resources and risk factors for personality development later in life, but that late-life patterns of stability and change in personality contribute to health declines in old age (see Human et al., 2013; Magee, Heaven, \& Miller, 2013; Turiano et al., 2012). Specifically, it has been suggested that changes in personality affect health through their influence on health behaviors and stress-related physiological processes (Friedman, 2000; Smith, 2006). For example, Takahashi, Edmonds, Jackson, and B. W. Roberts (2013) found that decreases in conscientiousness were associated with stronger declines in self-reported health and that changes in preventative health behaviors such as regular physical activity mediated this relationship. In a similar vein, increases in neuroticism, and thus heightened stress reactivity, have been shown to predict worse subjective health (Magee et al., 2013; Turiano et al., 2012). Studies with multiple assessments of personality and objective health variables as well as related behaviors are needed to disentangle and illuminate the complex pathways underlying personalityfunctioning interrelations. In order to move research one step further toward explicating and testing relevant mechanisms, it might also be highly informative to study personalityfunctioning dynamics across multiple time-scales and contexts (Fleeson \& Law, 2015; Gerstorf, Hoppmann, \& Ram, 2014; B. W. Roberts \& Jackson, 2008). One possible route of 
research could be to explore how daily adaptation dynamics contribute to and tie into the developmental trajectories observed on a larger time scale (over years and decades; see Hutteman, Nestler, Wagner, Egloff, \& Back, 2015 for a compelling example). For example, it is unclear how health constraints impact thoughts, feeling, and behavior on a day-to-day basis and how these patterns manifest in long-term personality change.

As limitations in our measures, we note that our analyses were based on relatively global trait-level information on the Big Five factors with limited reliability. Although we tried to account for the moderate reliability of the scales by modeling personality traits as latent variables, our findings should be replicated with more reliable and comprehensive personality measures. For example, previous research has reported initial evidence for the utility of examining more differentiated facet-level associations of personality and health (Sutin et al., 2013; Weiss \& Costa, 2005), which was not possible in this study. It is plausible that compromised health might affect some facets more strongly than others. To illustrate, it has been suggested that chronic health conditions might have a particularly strong effect on affective dynamics (Wahl, Heyl, \& Schilling, 2012) and emotion-related aspects of personality (e.g., the positive emotions facet of extraversion: Sutin et al., 2013). Additionally, one might expect stronger health-related changes in personality facets more closely tied to resource-dependent behaviors. For example, limited physical health and cognitive resources might lead to stronger decreases in orderliness and dutifulness, but leave other aspects of conscientiousness, such as deliberation, relatively unaffected. More fine-grained personality data could thus foster our understanding of the specific mechanisms that drive personalityfunctioning associations in old age.

We also note that we have targeted the role of three particular indicators out of a much broader construct space of physical health and cognitive functioning. To illustrate, we used a measure of cognitive functioning that predominantly taps into the more fluid aspects of intelligence and might thus not generalize to the broader level of cognitive abilities. For 
example, perceptual speed might be subjectively less salient for an individual than decline in other abilities such as episodic memory (Lövdén, Ghisletta, \& Lindenberger, 2005), which may be perceived as limiting one's functional capacity more immediately and in turn shape people's personality more directly. Similarly, recent findings suggest that crystallized intelligence might act as an important resource for stability and change in openness (von Stumm \& Deary, 2013; Ziegler et al., 2015). A comprehensive treatment of the question how particular personality domains relate to particular domains in the broader realms of physical and cognitive functioning would go beyond the scope of this initial effort and requires a systematic variation of a number of different dimensions on either side.

In addition to systematically investigating different aspects of physical and cognitive health, it might also be highly informative for future research to consider the role of social relations as an important context for personality development and successful aging (Antonucci \& Jackson, 1987; Hill et al., 2012; B. W. Roberts \& Wood, 2006). For example, a recent study examining personality-health associations in older couples found that wives' personality was associated with husbands' health status and vice versa, suggesting that developmental trajectories are closely interrelated within couples (B. W. Roberts, Smith, Jackson, \& Edmonds, 2009; see also Hoppmann \& Gerstorf, 2009). Caregiving duties might be one potential mechanism driving such associations, as taking care of one's sick spouse may require emotional and behavioral adjustments that have a lasting effect on personality traits (see Rohr, Wagner, \& Lang, 2013). As such, health constraints of close others might influence an individual's personality development above and beyond his or her own health status.

Finally, we acknowledge that the generalizability of our sample is limited. First, we only included residents from the metropolitan area of Berlin (Germany). While the use of such a community-based sample facilitates the assessment of comprehensive health data that is only very rarely obtained in larger surveys, our findings are based on a quite specific group 
of people and might therefore not apply to individuals from other parts of the Western world or beyond. We thus encourage future studies to corroborate our results in other and more heterogeneous samples. Second, given the age range of our sample (65 to 88 ) it remains an open question whether our results generalize to the very last years of life (for overview, see Gerstorf \& Ram, 2013). Based on life span developmental theory (Baltes et al., 2006; Baltes \& Smith, 2003) and initial empirical evidence (Wagner et al., 2015), we would expect personality-functioning associations to become even stronger with advancing age because an increasingly negative ratio of gains to losses limits the ability of the personality system to withstand the deleterious effects of declining health. In addition to age-related and pathologyrelated processes, personality development at the very end of life might also be affected by mortality-related processes that are not entirely captured by chronological age or health (Hülür, Ram, \& Gerstorf, in press; Gerstorf \& Ram, 2013). It would therefore be intriguing to also examine how proximity to death might shape patterns of late-life personality development (see Wagner et al., 2015 for initial evidence).

\section{Conclusions}

In closing, in the present study we applied latent growth models to three-wave personality data from the Berlin Aging Study II (BASE-II) and examined how personality traits and their changes relate to specific indicators of physical health and cognitive functioning. Our results both corroborate and extend previous findings showing that (1) latelife personality development is characterized by both stability and change, (2) patterns of stability and change in personality are related to physician-assessed and performance-based indicators of physical health and cognitive functioning, and (3) several of these associations are moderated by age and gender. Overall, our findings are consistent with life span developmental theory suggesting that age-related functioning in the physical and cognitive domains is associated with late-life personality and changes therein. 


\section{References}

Aartsen, M. J., Smits, C. H. M., van Tilburg, T., Knipscheer, K. C. P. M., \& Deeg, D. J. H. (2002). Activity in older adults: cause or consequence of cognitive functioning? A longitudinal study on everyday activities and cognitive performance in older adults. Journals of Gerontology: Series B: Psychological Sciences and Social Sciences, 57, 153-162. doi:10.1093/geronb/57.2.P153

Ambrasat, J., Schupp, J., \& Wagner, G. G. (2011). Comparing the predictive power of subjective and objective health indicators: Changes in hand grip strength and overall satisfaction with life as predictors of mortality. SOEP Paper, 398.

Aldwin, C. M., Spiro, A. I., Levenson, M. R., \& Cupertino, A. P. (2001). Longitudinal findings from the Normative Aging Study: III. Personality, individual health trajectories, and mortality. Psychology and Aging, 16, 450-465. doi:10.1037/0882-7974.16.3.450

Antonucci, T. C., \& Akiyama, H. (1987). An examination of sex differences in social support among older men and women. Sex Roles, 17, 737-749. doi:10.1007/BF00287685

Antonucci, T. C., \& Jackson, J. S. (1987). Social support, interpersonal efficacy, and health: A life course perspective. In L. L. Carstensen \& B. A. Edelstein (Eds.), Handbook of clinical gerontology. (pp. 291-311). Elmsford,NY: Pergamon Press.

Ardelt, M. (2000). Still stable after all these years? Personality stability theory revisited. Social Psychology Quarterly, 63, 392-405. doi: 10.2307/2695848

Baltes, P. B., \& Baltes, M. M. (1990). Psychological perspectives on successful aging: The model of selective optimization with compensation. In P. B. Baltes \& M. M. Baltes (Eds.), Successful aging: Perspectives from the behavioral sciences (pp. 1-34). New York, NY: Cambridge University Press. 
Baltes, P. B., Lindenberger, U., \& Staudinger, U. M. (2006). Life span theory in developmental psychology. In R. M. Lerner (Ed.), Handbook of child psychology: Theoretical models of human development (6th ed., Vol. 1, pp. 569-664). New York: Wiley.

Baltes, P. B., \& Smith, J. (2003). New frontiers in the future of aging: From successful aging of the young old to the dilemmas of the fourth age. Gerontology, 49, 123-35. doi:10.1159/000067946

Berg, A. I., \& Johansson, B. (2014). Personality change in the oldest-old: Is it a matter of compromised health and functioning? Journal of Personality, 82, 25-31. doi:10.1111/jopy.12030

Bertram, L., Böckenhoff, A., Demuth, I., Düzel, S., Eckardt, R., Li, S.-C., ... SteinhagenThiessen, E. (2014). Cohort profile: The Berlin Aging Study II (BASE-II). International Journal of Epidemiology, 43, 703-12. doi:10.1093/ije/dyt018

Bosworth, H. B., Schaie, K. W., \& Willis, S. L. (1999). Cognitive and sociodemographic risk factors for mortality in the Seattle Longitudinal Study. Journals of Gerontology: Series B: Psychological Sciences and Social Sciences, 54, 273-82. doi:10.1093/geronb/54B.5.P273

Caspi, A., Roberts, B. W., \& Shiner, R. L. (2005). Personality development: stability and change. Annual Review of Psychology, 56, 453-84. doi:10.1146/annurev.psych.55.090902.141913

Chapman, B. P., Duberstein, P. R., Sörensen, S., \& Lyness, J. M. (2007). Gender differences in Five Factor Model personality traits in an elderly cohort: Extension of robust and surprising findings to an older generation. Personality and Individual Differences, 43, 1594-1603. doi:10.1016/j.paid.2007.04.028

Chapman, B. P., Roberts, B. W., \& Duberstein, P. (2011). Personality and longevity: Knowns, unknowns, and implications for public health and personalized medicine. Journal of Aging Research, 2011, 1-24. doi:10.4061/2011/759170 
Charlson, M. E., Pompei, P., Ales, K. L., \& MacKenzie, C. R. (1987). A new method of classifying prognostic comorbidity in longitudinal studies: development and validation. Journal of Chronic Diseases, 40, 373-383. doi:10.1016/0021-9681(87)90171-8

Costa, P. T., \& McCrae, R. R. (1994). Set like plaster? Evidence for the stability of adult personality. In T. F. Heatherton \& J. L. Weinberger (Eds.), Can personality change? (pp. 21-40). Washington, DC: American Psychological Association.

DeYoung, C. G. (2011). Intelligence and personality. In R. J. Sternberg \& S. B. Kaufman (Eds.), The Cambridge handbook of intelligence (pp. 711-737). New York: Cambridge University Press.

Digman, J. M. (1997). Higher-order factors of the Big Five. Journal of Personality and Social Psychology, 73, 1246-1256. doi:10.1037/0022-3514.91.6.1138

Eagly, A. (1987). Sex differences in social behavior: A social-role interpretation. Hillsdale, NJ: Erlbaum.

Enders, C. K. (2010). Applied missing data analysis. New York: Guilford Publications.

Enders, C. K., \& Bandalos, D. L. (2001). The relative performance of full information maximum likelihood estimation for missing data in structural equation models. Structural Equation Modeling, 8, 430-457. doi:10.1207/S15328007sem0803_5

Ferrer, E., Balluerka, N., \& Widaman, K. F. (2008). Factorial invariance and specification of second-order latent growth models. Methodology, 4, 22-36. doi:10.1027/16142241.4.1.22

Fleeson, W., \& Law, M. K. (2015). Trait enactments as density distributions: The role of actors, situations, and observers in explaining stability and variability. Journal of Personality and Social Psychology, 109, 1090-1104. doi:10.1037/a0039517

Friedman, H. S. (2000). Long-term relations of personality and health: Dynamisms, mechanisms, tropisms. Journal of Personality, 68, 1089-1107. doi:10.1111/14676494.00127 
Gerlitz, Y., \& Schupp, J. (2005). Zur Erhebung der Big-Five-basierten Persönlichkeitsmerkmale im SOEP [Assessment of Big Five personality characteristics in the SOEP]. German Institute of Economic Research (Research Notes 4). Berlin: DIW.

Gerstorf, D., Bertram, L., Lindenberger, U., Pawelec, G., Steinhagen-Thiessen, E., \& Wagner, G. G. (2016). The Berlin Aging Study II - An overview. Gerontology. doi:10.1159/000441495

Gerstorf, D., Hoppmann, C. A., \& Ram, N. (2014). The promise and challenges of integrating multiple time-scales in adult developmental inquiry. Research in Human Development, 11, 75-90. doi:10.1080/15427609.2014.906725

Gerstorf, D., Hülür, G., Drewelies, J., Eibich, P., Düzel, S., Demuth, I., Ghisletta, P., Steinhagen-Thiessen, E., Wagner, G. G., \& Lindenberger, U. (2015). Secular changes in late-life cognition and well-being: Towards a long bright future with a short brisk ending? Psychology and Aging, 30, 301-310. doi:10.1037/pag0000016

Gerstorf, D., \& Ram, N. (2013). Inquiry into terminal decline: Five objectives for future study. The Gerontologist, 53, 727-737. doi:10.1093/geront/gnt046.

Goodwin, R. D., \& Friedman, H. S. (2006). Health status and the five-factor personality traits in a nationally representative sample. Journal of Health Psychology, 11, 643-54. doi:10.1177/1359105306066610

Graham, E. K., \& Lachman, M. E. (2012). Personality stability is associated with better cognitive performance in adulthood: Are the stable more able? Journals of Gerontology: Series B: Psychological Sciences and Social Sciences, 67, 545-554. doi:10.1093/geronb/gbr149

Hampson, S. E., Edmonds, G. W., Barckley, M., Goldberg, L. R., Dubanoski, J. P., \& Hillier, T. A. (2016). A Big Five approach to self-regulation: Personality traits and health trajectories in the Hawaii longitudinal study of personality and health. Psychology, Health \& Medicine, 21, 152-62. doi:10.1080/13548506.2015.1061676 
Hilgert, L., Kroh, M., \& Richter, D. (under review). The effect of face-to-face interviewing on personality measurement.

Hill, P. L., Turiano, N. A., Mroczek, D., \& Roberts, B. W. (2012). Examining concurrent and longitudinal relations between personality traits and social well-being in adulthood. Social Psychological and Personality Science, 3, 698-705. doi: $10.1177 / 1948550611433888$

Hooker, K., \& McAdams, D. P. (2003). Personality reconsidered: A new agenda for aging research. Journals of Gerontology: Series B: Psychological Sciences and Social Sciences, 58, 296-304. doi:10.1093/geronb/58.6.P296

Hoppmann, C. A., \& Gerstorf, D. (2009). Spousal interrelations in old age - a mini-review. Gerontology, 55, 449-59. doi:10.1159/000211948

Hoyer, W. J., Stawski, R. S., Wasylyshyn, C., \& Verhaeghen, P. (2004). Adult age and digit symbol substitution performance: a meta-analysis. Psychology and Aging, 19, 211-214. doi:10.1037/0882-7974.19.1.211

Hülür, G., Ram, N., \& Gerstorf, D. (in press). Terminal decline of function. In V. L. Bengtson \& R. A. Settersten, Jr. (Eds.), Handbook of Theories of Aging (3rd ed.). New York, NY: Springer.

Human, L. J., Biesanz, J. C., Miller, G. E., Chen, E., Lachman, M. E., \& Seeman, T. E. (2013). Is change bad? Personality change is associated with poorer psychological health and greater metabolic syndrome in midlife. Journal of Personality, 81, 249-260. doi:10.1111/jopy.12002

Hutteman, R., Hennecke, M., Orth, U., Reitz, A. K., \& Specht, J. (2014). Developmental tasks as a framework to study personality development in adulthood and old age. European Journal of Personality, 28, 267-278. doi:10.1002/per.1959

Hutteman, R., Nestler, S., Wagner, J., Egloff, B., \& Back, M. D. (2015). Wherever I may roam: Processes of self-esteem development from adolescence to emerging adulthood in 
the context of international student exchange. Journal of Personality and Social Psychology, 108, 767-83. doi:10.1037/pspp0000015

Jackson, J. J., Hill, P. L., Payne, B. R., Roberts, B. W., \& Stine-Morrow, E. A. L. (2012). Can an old dog learn (and want to experience) new tricks? Cognitive training increases openness to experience in older adults. Psychology and Aging, 27, 286-292. doi:10.1037/a0025918

Jerram, K. L., \& Coleman, P. G. (1999). The Big Five personality traits and reporting of health problems and health behaviour in old age. British Journal of Health Psychology, 4, 181192. doi:10.1348/135910799168560

John, O. P., \& Srivastava, S. (1999). The Big Five trait taxonomy: History, measurement, and theoretical perspectives. In L. Pervin \& O. John (Eds.), Handbook of personality theory and research (pp. 102-138). New York: Guilford.

Jokela, M., Hakulinen, C., Singh-Manoux, A, \& Kivimäki, M. (2014). Personality change associated with chronic diseases: pooled analysis of four prospective cohort studies. Psychological Medicine, 44, 2629-40. doi:10.1017/S0033291714000257

Kandler, C., Kornadt, A. E., Hagemeyer, B., \& Neyer, F. J. (2015). Patterns and sources of personality development in old age. Journal of Personality and Social Psychology, 109, 175-191. doi:10.1037/pspp0000028

Köhncke, Y., Laukka, E. J., Brehmer, Y., Kalpouzos, G., Li, T.-Q., Fratiglioni, L., ... Lövdén, M. (2016). Three-year changes in leisure activities are associated with concurrent changes in white matter microstructure and perceptual speed in individuals aged 80 years and older. Neurobiology of Aging, 41, 173-86.

doi:10.1016/j.neurobiolaging.2016.02.013

Lang, F. R., John, D., Lüdtke, O., Schupp, J., \& Wagner, G. G. (2011). Short assessment of the Big Five: robust across survey methods except telephone interviewing. Behavior Research Methods, 43, 548-567. doi:10.3758/s13428-011-0066-z 
Letzring, T. D., Edmonds, G. W., \& Hampson, S. E. (2014). Personality change at mid-life is associated with changes in self-rated health: Evidence from the Hawaii Personality and Health Cohort. Personality and Individual Differences, 58, 60-64. doi:10.1016/j.paid.2013.10.002

Lindenberger, U., \& Ghisletta, P. (2009). Cognitive and sensory declines in old age: gauging the evidence for a common cause. Psychology and Aging, 24, 1-16. doi:10.1037/a0014986

Lindenberger, U., Mayr, U., \& Kliegl, R. (1993). Speed and intelligence in old age. Psychology and Aging, 8, 207-220. doi:10.1037/0882-7974.8.2.207

Lövdén, M., Ghisletta, P., \& Lindenberger, U. (2005). Social participation attenuates decline in perceptual speed in old and very old age. Psychology and Aging, 20, 423-434. doi:10.1037/0882-7974.20.3.423

Lucas, R. E., \& Donnellan, M. B. (2011). Personality development across the life span: longitudinal analyses with a national sample from Germany. Journal of Personality and Social Psychology, 101, 847-61. doi:10.1037/a0024298

Magee, C. A, Heaven, P. C. L., \& Miller, L. M. (2013). Personality change predicts selfreported mental and physical health. Journal of Personality, 81, 324-34. doi:10.1111/j.1467-6494.2012.00802.x

Meredith, W., \& Teresi, J. A. (2006). An essay on measurement and factorial invariance. Medical Care, 44, S69-S77. doi:10.1097/01.mlr.0000245438.73837.89

Meyer, A., Salewsky, B., Spira, D., Steinhagen-Thiessen, E., Norman, K., \& Demuth, I. (2016). Leukocyte telomere length is related to appendicular lean mass: cross-sectional data from the Berlin Aging Study II (BASE-II). American Journal of Clinical Nutrition, 103, 178-183. doi:10.3945/ajen.115.116806 
Mõttus, R., Johnson, W., \& Deary, I. J. (2012). Personality traits in old age: Measurement and rank-order stability and some mean-level change. Psychology and Aging, 27, 243-249. doi:10.1037/a0023690

Mõttus, R., Johnson, W., Starr, J. M., \& Deary, I. J. (2012). Correlates of personality trait levels and their changes in very old age: The Lothian Birth Cohort 1921. Journal of Research in Personality, 46, 271-278. doi:10.1016/j.jrp.2012.02.004

Mroczek, D. K., \& Spiro, A. (2003). Modeling intraindividual change in personality traits: Findings from the Normative Aging Study. Journals of Gerontology: Series B: Psychological Sciences and Social Sciences, 58, 153-165. doi:10.1093/geronb/58.3.P153

Mroczek, D. K., \& Spiro, A. (2007). Personality change influences mortality in older men. Psychological Science, 18, 371-6. doi:10.1111/j.1467-9280.2007.01907.x

Mueller, S., Wagner, J., \& Gerstorf, D. (in press). On the role of personality in late life. In J. Specht (Ed.), Personality development across the lifespan. San Diego, CA: Elsevier.

Muthén, L. K., \& Muthén, B. O. (1998-2012). Mplus User’s Guide. Los Angeles, CA: Muthén \& Muthén.

Newsom, J. T. (2015). Longitudinal structural equation modeling: A comprehensive introduction. New York: Routledge.

Ram, N., Gerstorf, D., Lindenberger, U., \& Smith, J. (2011). Developmental change and intraindividual variability: Relating cognitive aging to cognitive plasticity, cardiovascular lability, and emotional diversity. Psychology and Aging, 26, 363-371. doi:10.1037/a0021500

Raudenbush, S. W., \& Bryk, A. S. (2002). Hierarchical linear models: Applications and data analysis methods (2nd ed.). Thousand Oaks, CA: Sage.

Roberts, B. W., \& Jackson, J. J. (2008). Sociogenomic personality psychology. Journal of Personality, 76, 1523-44. doi:10.1111/j.1467-6494.2008.00530.x 
Roberts, B. W., Smith, J., Jackson, J. J., \& Edmonds, G. (2009). Compensatory conscientiousness and health in older couples. Psychological Science, 20, 553-9. doi:10.1111/j.1467-9280.2009.02339.x

Roberts, B. W., Walton, K. E., \& Viechtbauer, W. (2006). Patterns of mean-level change in personality traits across the life course: a meta-analysis of longitudinal studies. Psychological Bulletin, 132, 1-25. doi:10.1037/0033-2909.132.1.1

Roberts, B. W., \& Wood, D. (2006). Personality development in the context of the neosocioanalytic model of personality. In D. K. Mroczek \& T. D. Little (Eds.), Handbook of personality development (pp. 11-39). Mahwah NJ: Lawrence Erlbaum Associates Publishers.

Roberts, B. W., Wood, D., \& Caspi, A. (2008). The development of personality traits in adulthood. In O. P. John, R. W. Robins, \& L. A. Pervin (Eds.), Handbook of personality: Theory and research (3rd ed., pp. 375-398). New York, NY: Guilford Press.

Roberts, H. C., Denison, H. J., Martin, H. J., Patel, H. P., Syddall, H., Cooper, C., \& Sayer, A. A. (2011). A review of the measurement of grip strength in clinical and epidemiological studies: Towards a standardised approach. Age and Ageing, 40, 423-429. doi:10.1093/ageing/afr051

Rohr, M. K., Wagner, J., \& Lang, F. R. (2013). Effects of personality on the transition into caregiving. Psychology and Aging, 28, 692-700. doi:10.1037/a0034133

Salthouse, T. A. (1996). The processing-speed theory of adult age differences in cognition. Psychological Review, 103, 403-428. doi:10.1037/0033-295X.103.3.403

Schafer, J. L., \& Graham, J. W. (2002). Missing data: our view of the state of the art. Psychological Methods, 7, 147-177. doi:10.1037/1082-989X.7.2.147

Schmitt, D. P., Realo, A., Voracek, M., \& Allik, J. (2008). Why can't a man be more like a woman? Sex differences in Big Five personality traits across 55 cultures. Journal of Personality and Social Psychology, 94, 168-182. doi:10.1037/0022-3514.94.1.168 
Smith, T. W. (2006). Personality as risk and resilience in physical health. Current Directions in Psychological Science, 15, 227-231. doi:10.1111/j.1467-8721.2006.00441.x

Specht, J., Bleidorn, W., Denissen, J. J. A., Hennecke, M., Hutteman, R., Kandler, C., ... Zimmermann, J. (2014). What drives adult personality development? A comparison of theoretical perspectives and empirical evidence. European Journal of Personality, 28, 216-230. doi:10.1002/per.1966

Specht, J., Egloff, B., \& Schmukle, S. C. (2011). Stability and change of personality across the life course: the impact of age and major life events on mean-level and rank-order stability of the Big Five. Journal of Personality and Social Psychology, 101, 862-82. doi: $10.1037 / \mathrm{a} 0024950$

Staudinger, U. M., \& Fleeson, W. (1996). Self and personality in old and very old age: A sample case of resilience? Development and Psychopathology, 8, 867-885. doi:10.1017/S0954579400007471

Staudinger, U. M., \& Kunzmann, U. (2005). Positive Adult Personality Development. European Psychologist, 10, 320-329. doi:10.1027/1016-9040.10.4.320

Steinhagen-Thiessen, E., \& Borchelt, M. (1999). Morbidity, medication, and functional limitations in very old age. In P. B. Baltes \& K. Mayer (Eds.), The Berlin Aging Study: Aging from 70 to 100 (pp. 131-166). Cambridge: Cambridge University Press.

Sutin, A. R., Zonderman, A. B., Ferrucci, L., \& Terracciano, A. (2013). Personality traits and chronic disease: implications for adult personality development. Journals of Gerontology: Series B: Psychological Sciences and Social Sciences, 68, 912-20. doi:10.1093/geronb/gbt036

Taekema, D. G., Gussekloo, J., Maier, A. B., Westendorp, R. G. J., \& de Craen, A. J. M. (2010). Handgrip strength as a predictor of functional, psychological and social health. A prospective population-based study among the oldest old. Age and Ageing, 39, 331-7. doi:10.1093/ageing/afq022 
Takahashi, Y., Edmonds, G. W., Jackson, J. J., \& Roberts, B. W. (2013). Longitudinal correlated changes in conscientiousness, preventative health-related behaviors, and selfperceived physical health. Journal of Personality, 81, 417-27. doi:10.1111/jopy.12007

Tucker-Drob, E. M., Briley, D. A, Starr, J. M., \& Deary, I. J. (2014). Structure and correlates of cognitive aging in a narrow age cohort. Psychology and Aging, 29, 236-49. doi:10.1037/a0036187

Turiano, N. A., Pitzer, L., Armour, C., Karlamangla, A., Ryff, C. D., \& Mroczek, D. K. (2012). Personality trait level and change as predictors of health outcomes: findings from a national study of Americans (MIDUS). Journals of Gerontology: Series B: Psychological Sciences and Social Sciences, 67, 4-12. doi:10.1093/geronb/gbr072

Von Stumm, S., \& Deary, I. J. (2013). Intellect and cognitive performance in the Lothian Birth Cohort 1936. Psychology and Aging, 28, 680-4. doi:10.1037/a0033924

Wagner, J., Ram, N., Smith, J., \& Gerstorf, D. (2015). Personality trait development at the end of life: Antecedents and correlates of mean-level trajectories. Journal of Personality and Social Psychology. Advance online publication. doi:10.1037/pspp0000071

Wahl, H. W., Heyl, V., \& Schilling, O. (2012). Robustness of personality and affect relations under chronic conditions: the case of age-related vision and hearing impairment. Journals of Gerontology: Series B: Psychological Sciences and Social Sciences, 67, 687-96. doi:10.1093/geronb/gbs002

Wechsler, D. (1955). Manual for the Wechsler Adult Intelligence Scale. New York: Psychological Corporation.

Weiss, A., \& Costa, P. T. (2005). Domain and facet personality predictors of all-cause mortality among Medicare patients aged 65 to 100. Psychosomatic Medicine, 67, 72433. doi:10.1097/01.psy.0000181272.58103.18 
Widaman, K. F., Ferrer, E., \& Conger, R. D. (2010). Factorial invariance within longitudinal structural equation models: Measuring the same construct across time. Child Development Perspectives, 4, 10-18. doi:10.1111/j.1750-8606.2009.00110.x

Wortman, J., Lucas, R. E., \& Donnellan, M. B. (2012). Stability and change in the Big Five personality domains: Evidence from a longitudinal study of Australians. Psychology and Aging, 27, 867-874. doi:10.1037/a0029322

Wrzus, C., Hänel, M., Wagner, J., \& Neyer, F. J. (2013). Social network changes and life events across the life span: a meta-analysis. Psychological Bulletin, 139, 53-80. doi:10.1037/a0028601

Wrzus, C., \& Roberts, B.W. (in press). Processes of personality development in adulthood: The TESSERA Framework. Personality and Social Psychology Review.

Ziegler, M., Cengia, A., Mussel, P., \& Gerstorf, D. (2015). Openness as a buffer against cognitive decline: The Openness-Fluid-Crystallized-Intelligence (OFCI) model applied to late adulthood. Psychology and Aging, 30, 573-588. doi:10.1037/a0039493 


\section{Author Notes}

Swantje Mueller, Humboldt University, Berlin, Germany; Jenny Wagner, Leibniz Institute for Science and Mathematics Education (IPN), Kiel, Germany and Humboldt University, Berlin, Germany; Johanna Drewelies, Humboldt University, Berlin, Germany; Sandra Duezel, Max Planck Institute for Human Development, Berlin, Germany; Peter Eibich, University of Oxford, UK; Jule Specht, Freie Universität Berlin, Berlin, Germany and German Institute for Economic Research (DIW Berlin), Berlin, Germany; Ilja Demuth, Charite - Universitätsmedizin Berlin, Germany; Elisabeth Steinhagen-Thiessen, Charite Universitätsmedizin Berlin, Germany; Gert G. Wagner, Max Planck Institute for Human Development, Berlin, German Institute for Economic Research, Berlin, and Berlin University of Technology, Germany; Denis Gerstorf, Humboldt University, Berlin, Germany and German Institute for Economic Research (DIW Berlin), Berlin, Germany.

This article reports data from the Berlin Aging Study II (BASE-II). The BASE-II research project (Co-PIs are Lars Bertram, Denis Gerstorf, Ulman Lindenberger, Graham Pawelec, Elisabeth Steinhagen-Thiessen and Gert G. Wagner) is supported by the German Federal Ministry of Education and Research (Bundesministerium für Bildung und Forschung, BMBF) under grant numbers \#16SV5536K, \#16SV5537, \#16SV5538, and \#16SV5837, and \#01UW0808). Another source of funding is the Max Planck Institute for Human Development, Berlin, Germany. Additional contributions (e.g. equipment, logistics, personnel) are made from each of the other participating sites. Further details about the study can be obtained at https://www.base2.mpg.de/en. Swantje Mueller and Johanna Drewelies are funded by the International Max Planck Research School (LIFE, www.imprs-life.mpg.de).

e-mail: swantje.mueller@hu-berlin.de; jwagner@ipn.uni-kiel.de;

johanna.drewelies@hu-berlin.de; duezel@mpib-berlin.mpg.de; peter.eibich@dph.ox.ac.uk; jule.specht@fu-berlin.de; ilja.demuth@charite.de; elisabeth.steinhagen-thiessen@charite.de; gwagner@mpib-berlin.mpg.de; denis.gerstorf@hu-berlin.de. 
Table 1

Descriptive Statistics and Intercorrelations Among Study Variables

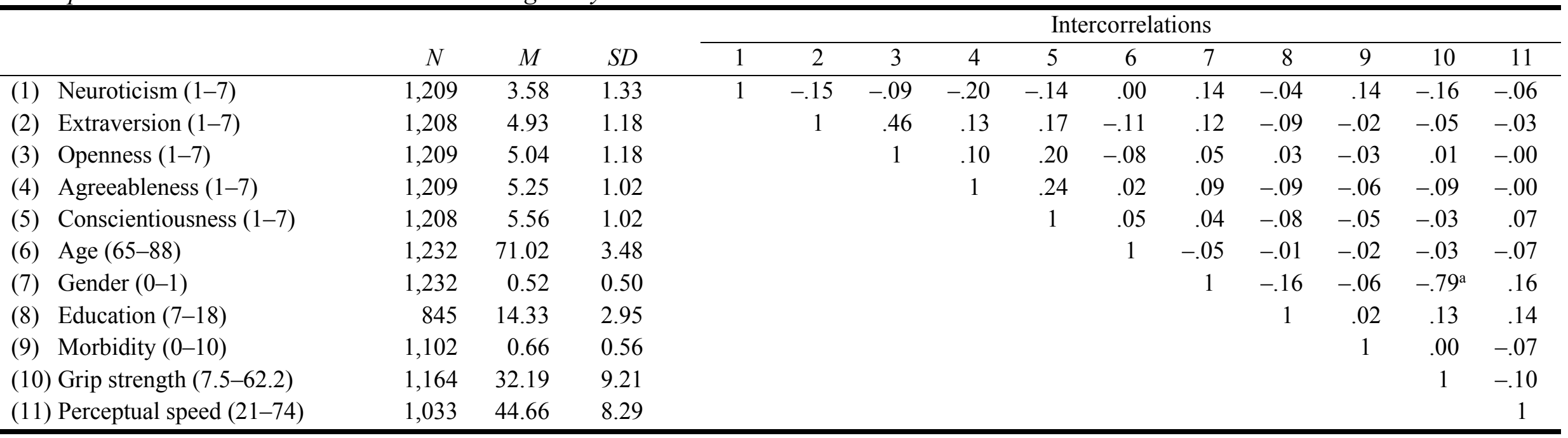

Note. Personality traits are presented as manifest variables. Personality information presented here refers to the last wave of personality data assessed in 2013/4. For information on intercorrelations among personality traits across time please refer to Table 2 . Gender was coded 0 for men and 1 for women. Intercorrelations of $r=|.07|$ or above are reliably different from zero at $p<.05$.

${ }^{a}$ A high zero-order correlation between gender and grip strength is to be expected because grip strength was used as an indicator. Gender differences are controlled for in the latent growth models. 
Table 2

Descriptive Statistics and Intercorrelations Among Personality Traits Across Time

\begin{tabular}{|c|c|c|c|c|c|c|c|c|c|c|c|c|c|c|c|c|c|c|c|c|}
\hline \multirow[b]{2}{*}{ Wave } & & & \multirow[b]{2}{*}{$N$} & \multirow[b]{2}{*}{$M$} & \multirow[b]{2}{*}{$S D$} & \multicolumn{15}{|c|}{ Intercorrelations } \\
\hline & & & & & & 1 & 2 & 3 & 4 & 5 & 6 & 7 & 8 & 9 & 10 & 11 & 12 & 13 & 14 & 15 \\
\hline \multirow[t]{5}{*}{2009} & (1) & & 769 & 3.84 & 1.33 & 1 & -.09 & -.07 & -.12 & -.10 & .70 & -.08 & -.05 & -.14 & -.11 & .71 & -.09 & -.10 & -.17 & -.12 \\
\hline & & & 768 & 4.82 & 1.18 & & 1 & .39 & .05 & .18 & -.08 & .73 & .37 & .07 & .16 & -.07 & .74 & .39 & .09 & .15 \\
\hline & (3) & $\mathrm{O}$ & 769 & 4.95 & 1.20 & & & 1 & .12 & .19 & -.04 & .35 & .69 & .10 & .13 & -.04 & .41 & .73 & .04 & .13 \\
\hline & (4) & A & 769 & 5.28 & 1.04 & & & & 1 & .18 & -.08 & .12 & .08 & .66 & .20 & -.07 & .07 & .10 & .61 & .16 \\
\hline & (5) & $\mathrm{C}$ & 768 & 5.68 & 1.01 & & & & & 1 & -.04 & .17 & .20 & .16 & .67 & -.07 & .17 & .20 & .19 & .69 \\
\hline \multirow[t]{5}{*}{2012} & (6) & $\mathrm{N}$ & 870 & 3.65 & 1.28 & & & & & & 1 & -.14 & -.05 & -.14 & -.14 & .77 & -.13 & -.06 & -.12 & -.11 \\
\hline & & & 870 & 4.75 & 1.15 & & & & & & & 1 & .41 & .12 & .19 & -.13 & .76 & .37 & .13 & .13 \\
\hline & (8) & $\mathrm{O}$ & 870 & 5.03 & 1.16 & & & & & & & & 1 & .13 & .21 & -.07 & .42 & .72 & .06 & .14 \\
\hline & (9) & & 870 & 5.24 & 0.99 & & & & & & & & & 1 & .22 & -.10 & .08 & .11 & .63 & .16 \\
\hline & (10) & $\mathrm{C}$ & 870 & 5.62 & 0.98 & & & & & & & & & & 1 & -.11 & .16 & .15 & .23 & .70 \\
\hline \multirow[t]{5}{*}{$2013 / 4$} & (11) & $\mathrm{N}$ & 1,209 & 3.58 & 1.33 & & & & & & & & & & & 1 & -.15 & -.09 & -.20 & -.14 \\
\hline & (12) & $\mathrm{E}$ & 1,208 & 4.93 & 1.18 & & & & & & & & & & & & 1 & .46 & .13 & .17 \\
\hline & (13) & $\mathrm{O}$ & 1,209 & 5.04 & 1.18 & & & & & & & & & & & & & 1 & .10 & .20 \\
\hline & (14) & A & 1,209 & 5.25 & 1.02 & & & & & & & & & & & & & & 1 & .24 \\
\hline & (15) & $\mathrm{C}$ & 1,208 & 5.56 & 1.02 & & & & & & & & & & & & & & & 1 \\
\hline
\end{tabular}

Note. Personality traits are presented as manifest variables. Intercorrelations of $r=|.08|$ or above are reliably different from zero at $p<.05$. 
Table 3

Latent Growth Models for the Five Personality Dimensions

\begin{tabular}{|c|c|c|c|c|c|c|c|c|c|c|}
\hline & \multicolumn{2}{|c|}{ Neuroticism } & \multicolumn{2}{|c|}{ Extraversion } & \multicolumn{2}{|c|}{ Openness } & \multicolumn{2}{|c|}{ Agreeableness } & \multicolumn{2}{|c|}{ Conscientiousness } \\
\hline & Estimate & $\mathrm{SE}$ & Estimate & $\mathrm{SE}$ & Estimate & SE & Estimate & $\mathrm{SE}$ & Estimate & $\mathrm{SE}$ \\
\hline \multicolumn{11}{|l|}{ Mean } \\
\hline Intercept & $3.58^{*}$ & 0.04 & $4.88 *$ & 0.03 & $5.07 *$ & 0.03 & $5.26^{*}$ & 0.03 & $5.58^{*}$ & 0.03 \\
\hline Slope & $-0.05^{*}$ & 0.01 & $0.02 *$ & 0.01 & $0.02 *$ & 0.01 & 0.01 & 0.01 & $-0.02 *$ & 0.01 \\
\hline \multicolumn{11}{|l|}{ Variance } \\
\hline Intercept & $1.21^{*}$ & 0.07 & $0.92 *$ & 0.08 & $0.83 *$ & 0.05 & $0.50^{*}$ & 0.03 & $0.58 *$ & 0.04 \\
\hline Slope & $0.02 *$ & 0.00 & $0.01 *$ & 0.00 & $0.01 *$ & 0.00 & $0.01 *$ & 0.00 & $0.01 *$ & 0.00 \\
\hline Cov intercept, slope & $0.05 *$ & 0.01 & 0.01 & 0.01 & 0.00 & 0.01 & 0.01 & 0.01 & $0.02 *$ & 0.01 \\
\hline AIC & $29,203.372$ & & $27,142.757$ & & $27,910.351$ & & $27,433.101$ & & $25,887.738$ & \\
\hline
\end{tabular}

Note. Cov intercept, slope $=$ Covariance between intercept and slope. Scores for personality range from 1-7. Unstandardized estimates and standard errors are presented. $* p<.05$. 
Table 4

Latent Growth Models for the Five Personality Dimensions, including Socio-Demographic Characteristics, Morbidity, Grip Strength, and Perceptual Speed

\begin{tabular}{|c|c|c|c|c|c|c|c|c|c|c|}
\hline & \multicolumn{2}{|c|}{ Neuroticism } & \multicolumn{2}{|c|}{ Extraversion } & \multicolumn{2}{|c|}{ Openness } & \multicolumn{2}{|c|}{ Agreeableness } & \multicolumn{2}{|c|}{ Conscientiousness } \\
\hline & Estimate & SE & Estimate & SE & Estimate & SE & Estimate & SE & Estimate & SE \\
\hline \multicolumn{11}{|l|}{ Intercept } \\
\hline Mean & $3.58 *$ & 0.04 & $4.89 *$ & 0.03 & $5.07 *$ & 0.03 & $5.26^{*}$ & 0.03 & $5.58 *$ & 0.03 \\
\hline Age & 0.00 & 0.01 & $-0.02 *$ & 0.01 & $-0.02 *$ & 0.01 & 0.00 & 0.01 & 0.01 & 0.01 \\
\hline Gender & $0.32 *$ & 0.09 & $0.26^{*}$ & 0.06 & -0.01 & 0.11 & $0.21 *$ & 0.05 & 0.02 & 0.06 \\
\hline Education & -0.01 & 0.01 & $-0.03 *$ & 0.01 & 0.01 & 0.01 & $-0.03 *$ & 0.01 & -0.01 & 0.01 \\
\hline Morbidity & $0.09^{*}$ & 0.02 & -0.01 & 0.02 & -0.02 & 0.02 & -0.02 & 0.01 & -0.00 & 0.02 \\
\hline Perceptual speed & $-0.89 *$ & 0.32 & -0.40 & 0.27 & -0.07 & 0.27 & -0.08 & 0.22 & $0.66^{*}$ & 0.24 \\
\hline \multicolumn{11}{|c|}{ Moderation with intercept } \\
\hline Grip strength $\times$ age & / & l & l & / & l & / & $-1.87^{*}$ & 0.82 & l & / \\
\hline Grip strength $\times$ gender & / & / & / & / & / & / & $0.19 *$ & 0.07 & / & / \\
\hline \multicolumn{11}{|l|}{ Slope } \\
\hline Mean & $-0.05^{*}$ & 0.01 & $0.03 *$ & 0.01 & $0.02 *$ & 0.01 & 0.01 & 0.01 & $-0.02 *$ & 0.01 \\
\hline Age & 0.00 & 0.00 & -0.003 & 0.00 & $-0.005 *$ & 0.00 & 0.00 & 0.00 & -0.00 & 0.00 \\
\hline Education & -0.00 & 0.00 & -0.00 & 0.00 & 0.00 & 0.00 & -0.00 & 0.00 & -0.00 & 0.00 \\
\hline Morbidity & 0.00 & 0.01 & -0.00 & 0.00 & -0.01 & 0.00 & -0.00 & 0.00 & -0.01 & 0.00 \\
\hline Grip strength & -0.07 & 0.05 & $0.11^{*}$ & 0.03 & 0.06 & 0.04 & $0.08^{*}$ & 0.03 & $0.07^{*}$ & 0.04 \\
\hline Perceptual speed & -0.04 & 0.07 & 0.02 & 0.05 & 0.09 & 0.06 & 0.03 & 0.06 & 0.03 & 0.05 \\
\hline \multicolumn{11}{|l|}{ Moderation with slope } \\
\hline Morbidity $\times$ age & / & l & / & / & / & / & l & l & $0.02 *$ & 0.01 \\
\hline Perceptual speed $\times$ age & l & / & $0.37 *$ & 0.16 & l & / & I & / & $0.38 *$ & 0.16 \\
\hline Morbidity $\times$ gender & / & / & l & / & / & / & $-0.004 *$ & 0.00 & / & / \\
\hline Grip strength $\times$ gender & l & / & l & l & l & / & / & l & $-0.04 *$ & 0.02 \\
\hline \multicolumn{11}{|l|}{ Variance } \\
\hline Intercept & $1.18^{*}$ & 0.13 & $0.88 *$ & 0.04 & $0.82 *$ & 0.15 & $0.48 *$ & 0.03 & $0.58 *$ & 0.04 \\
\hline Slope & $0.02 *$ & 0.00 & $0.01 *$ & 0.00 & $0.01 *$ & 0.00 & $0.01 *$ & 0.00 & $0.01 *$ & 0.00 \\
\hline Cov intercept, slope & $0.05 *$ & 0.01 & 0.01 & 0.01 & 0.00 & 0.01 & 0.01 & 0.01 & $0.02 *$ & 0.01 \\
\hline
\end{tabular}


Note. Cov intercept, slope = Covariance between intercept and slope. Scores for personality range from 1-7. Gender was coded 0 for men and 1 for

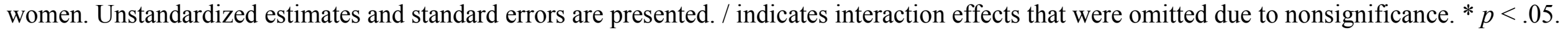




\section{Figure Captions}

Figure 1. Latent growth model for analyzing personality trait levels and changes and their association with morbidity, grip strength, and perceptual speed. Manifest variables are represented by squares. Latent variables are represented by circles. The triangle represents a constant to estimate the means and intercepts. Although not depicted in this figure, correlations of demographic variables with morbidity, grip strength, and perceptual speed as well as interaction terms for age and gender were additionally estimated (if reliably different from zero). Covariances between corresponding item-specific residuals were constrained to be equal over time.

Figure 2. Zero-order correlations of morbidity, grip strength, and perceptual speed with personality trait levels and changes by age (median-split). Grip strength and perceptual speed were centered; morbidity was log-transformed and centered. Lower grip strength is associated with higher agreeableness among older, but not younger participants (a). Conversely, higher morbidity is associated with accelerated decline in conscientiousness in young old, but not in old old individuals (b). Moreover, lower perceptual speed was associated with stronger increases (or attenuated decline) in extraversion and conscientiousness in young old participants, while old old individuals with compromised perceptual speed reported stronger decreases (or reduced increases) in both traits $(\mathrm{c}, \mathrm{d})$.

Figure 3. Zero-order correlations of morbidity and grip strength with personality trait levels and changes by gender. Grip strength was centered; morbidity was log-transformed and centered. Worse grip strength is associated with lower agreeableness in women, but with higher agreeableness in men (a). Additionally, higher morbidity is associated with decreases in agreeableness in women, but with increases in agreeableness in men (b). Finally, worse grip strength is associated with accelerated decline in conscientiousness in men only (c). 


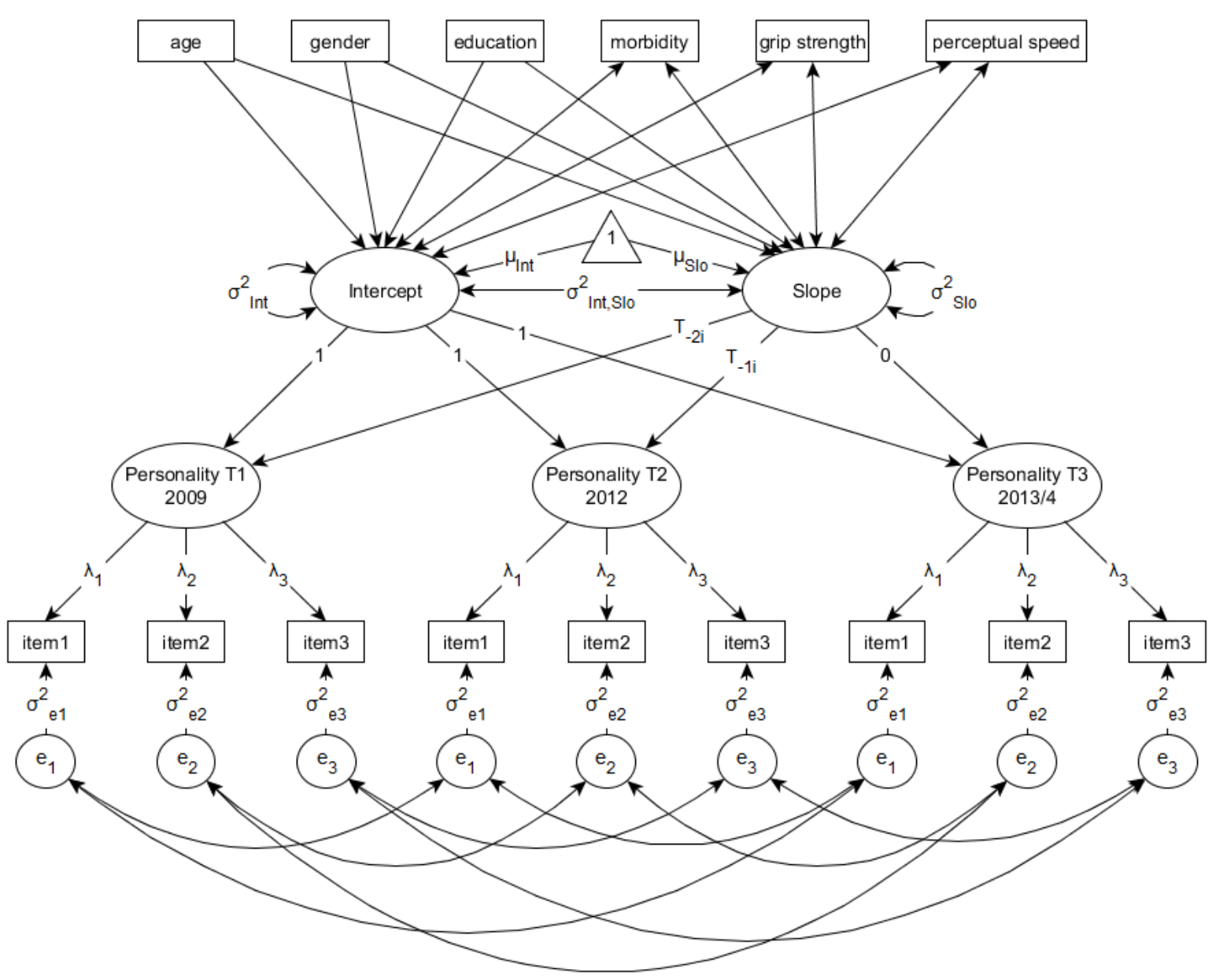



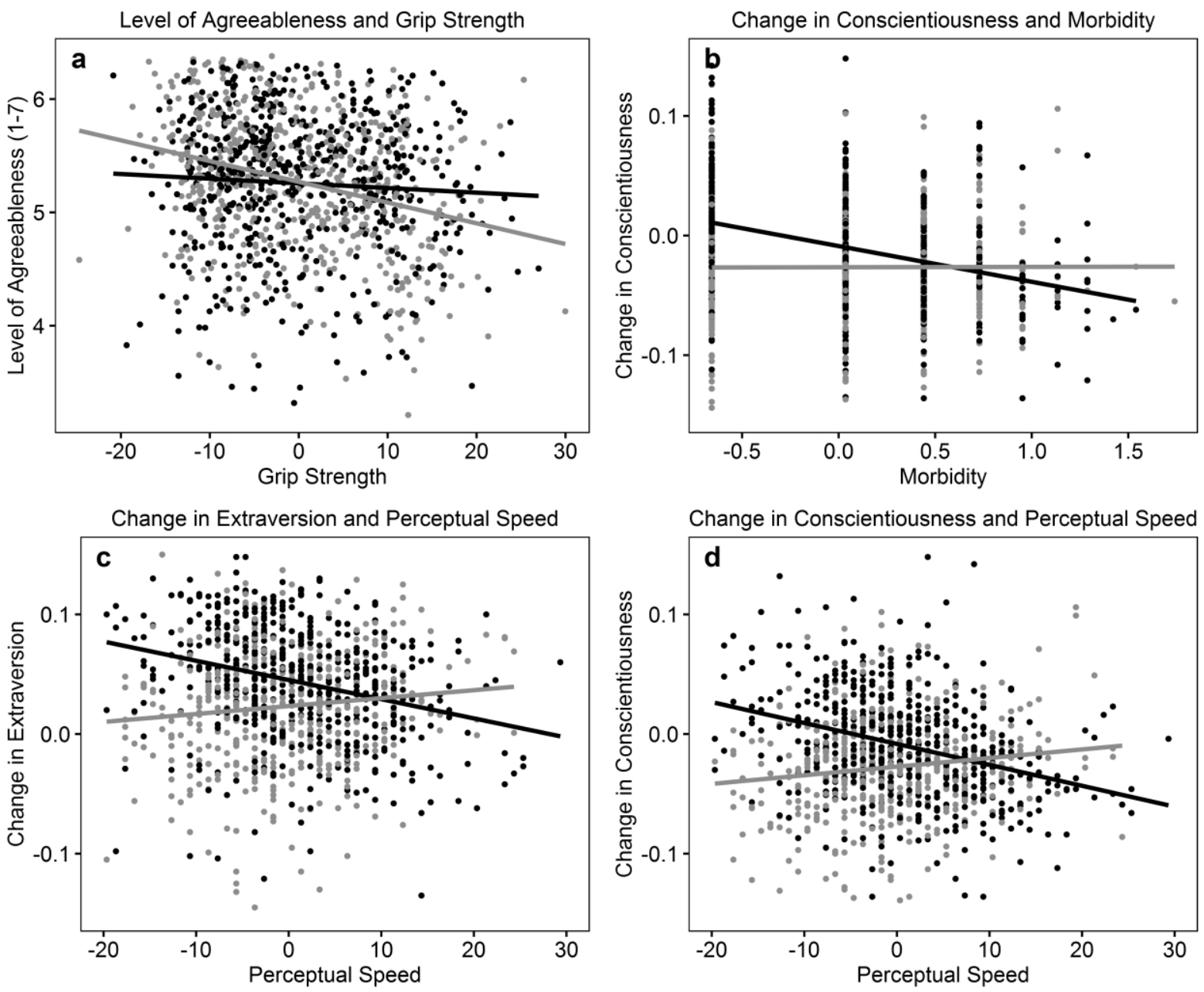

$$
\text { Age } \longrightarrow<=70->70
$$



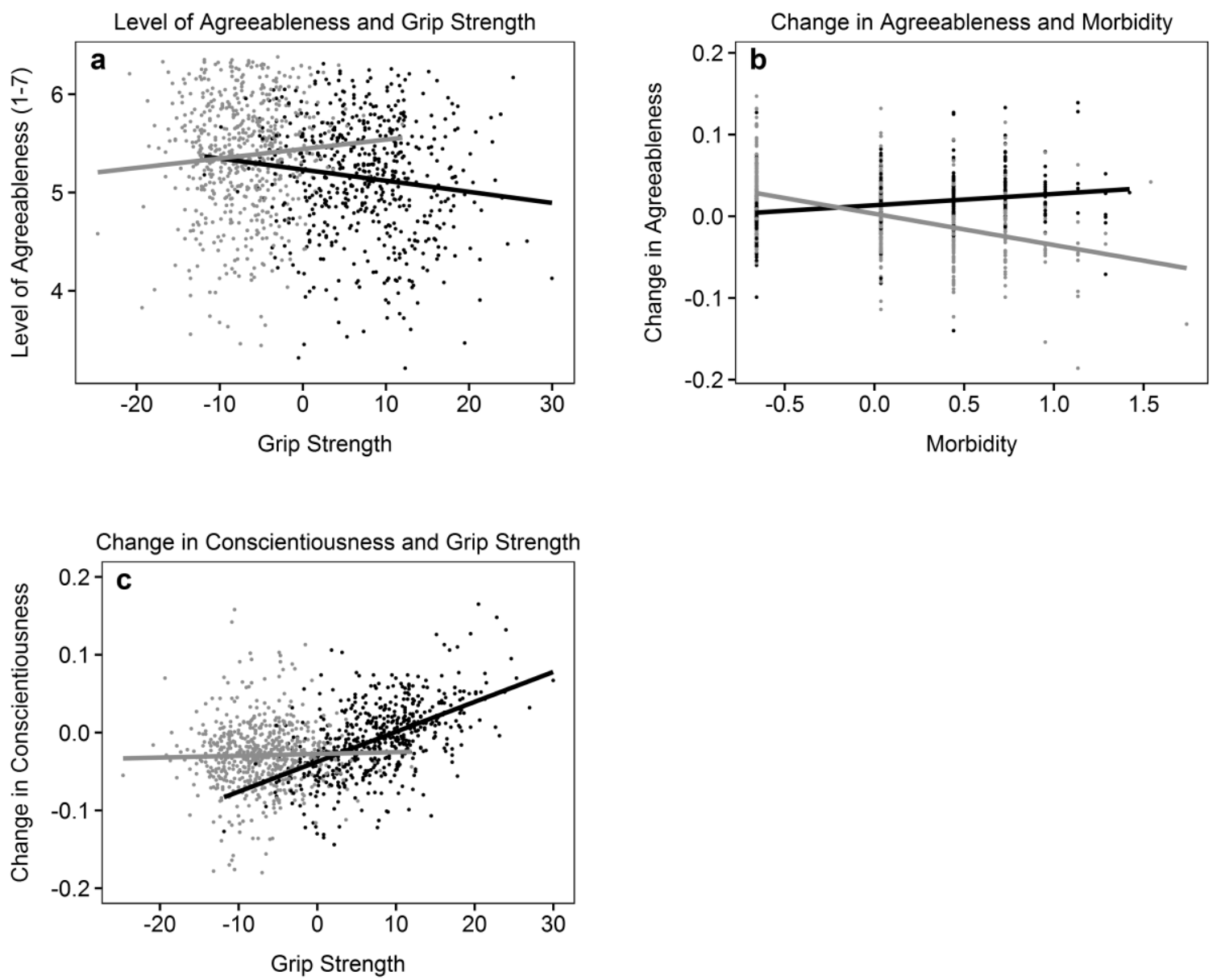

Gender - men - women 